\title{
Cell Death and Cancer, Novel Therapeutic Strategies
}

\author{
Silvina Grasso, M. Piedad Menéndez-Gutiérrez, \\ Estefanía Carrasco-García, Leticia Mayor-López, \\ Elena Tristante, Lourdes Rocamora-Reverte, \\ Ángeles Gómez-Martínez, Pilar García-Morales, \\ José A. Ferragut, Miguel Saceda and Isabel Martínez-Lacaci
}

Additional information is available at the end of the chapter

http://dx.doi.org/10.5772/51285

\section{Introduction}

\subsection{History, definition and classification}

Life and death are essential parts of the natural cycle of all multicellular organisms. In metazoans, somatic cells divide normally during the process known as mitosis. Cell proliferation is tightly controlled, according to the organism needs. An increase in the number of cells takes place during growth and when one of these cells finishes its physiological function or detects DNA or cell damage, it undergoes a physiological process known as apoptosis that induces its own death. In humans about a hundred thousand cells are formed every second through mitosis, while a similar number is destroyed by apoptosis [1]. This dynamic balance between proliferation and cell death is known as homeostasis. If altered, different pathologic processes such as carcinogenesis can take place. Besides its role in embryonic development, homeostasis maintenance and aging, apoptosis is also a defence mechanism by which infected, injured or mutated cells as a result of irradiation or chemotherapeutic drugs are eliminated. This type of cell death involves the activation of an evolutionary conserved and tightly regulated intracellular machinery that requires energy consumption [2]. An important feature of apoptosis is that the cell is eliminated without triggering an immune response, avoiding thus tissue damage [3].

The term apoptosis to describe cell death was introduced by Kerr and colleagues in 1972 [4], from the Greek term "appo-teo-sis" which means "falling off" (as in leaves from a tree or petals from a flower). Apoptosis has been used as a synonym of programmed cell death and 
refers to a suicidal type of death. However, as more mechanisms of programmed cell death are being elucidated, the Nomenclature Committee on Cell Death (NCCD) recommends caution when using the term apoptosis [5]. Historically, the classical methods to define cell death rely on morphological criteria. Thus, apoptosis was termed programmed cell death type I, autophagy named as programmed cell death type II and necrosis as a type of death lacking characteristics of both type I and type II. As more biochemical methods become available over the last decades, a more definite and concise classification of types of cell death has become necessary. Therefore, cell death types can be classified according to morphological appearance, biochemical features, functional criteria or immunological aspects. In the following figure (Figure 1) the classification of different types of cell death, in accordance with to the NCCD are described:

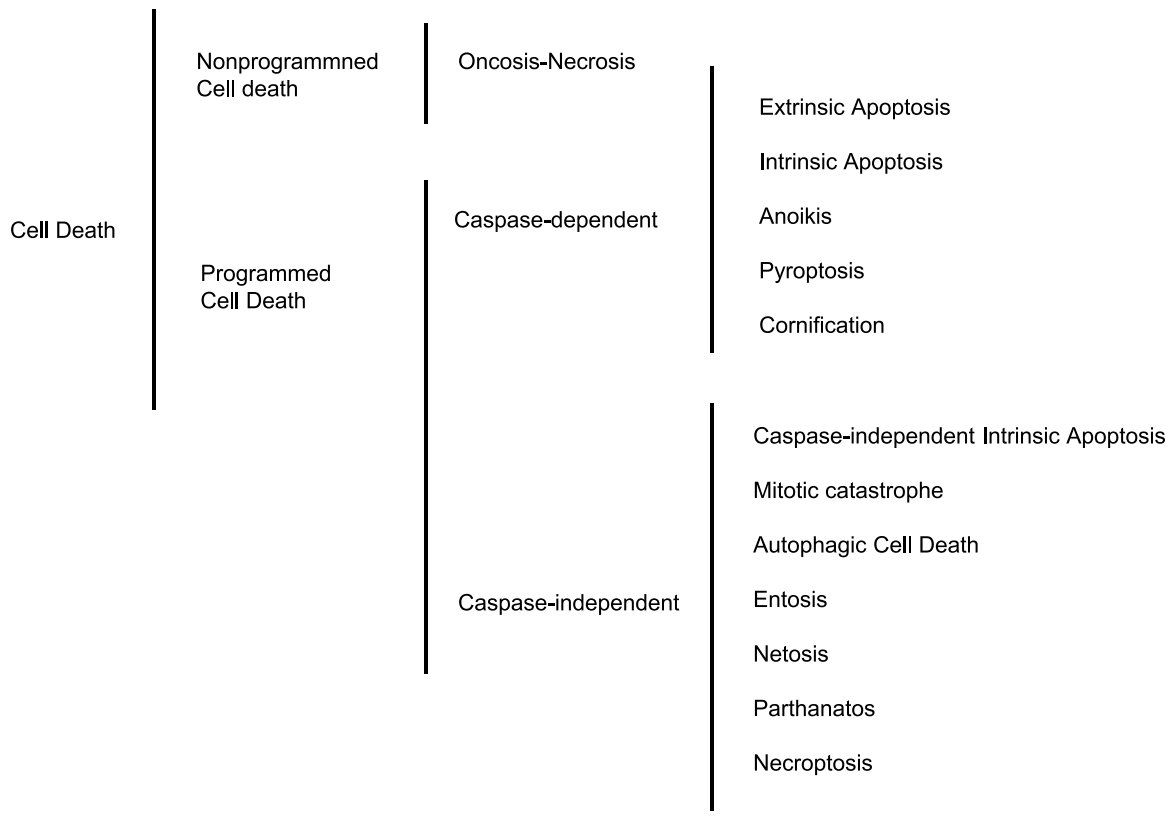

Figure 1. Classification of different types of cell death according to the NCCD (modified from Galluzzi et al. 2012)

It is important to mention that a single stimulus can trigger more than one mechanism of cell death simultaneously within a cell. However, only the most efficacious mechanism will be prevalent.

\section{Apoptosis}

\subsection{Morphological and biochemical features}

Morphological features that share both caspase-dependent and independent apoptotic pathways are: a) loss of plasma membrane symmetry and loss of cell-to-cell contact and cell 
round-up, b) chromatin condensation (picnosis) and fragmentation and nuclear breakdown, c) overall cell shrinkage and cytoskeleton alterations although the majority of the cell organelles remain intact, d) membrane blebbing and formation of the membrane-enclosed particles called apoptotic bodies that contain nuclear or cytoplasmic material and will be engulfed by phagocytes or neighbouring cells [6].

Because apoptotic cells are eaten so quickly, there are few dead cells left on tissue sections. This is the reason why apoptosis was neglected by pathologists for a long time, even though apoptosis is the main mechanism for discarding of harmful or unwanted cells in multicellular organisms.

Along with the morphological transformation described, there are several biochemical alterations that take place. For instance, activation of endonucleases, some of them dependent on $\mathrm{Ca}^{2+}$ and $\mathrm{Mg}^{2+}$ channels, that cleaves genomic DNA. In the apoptotic process, this event gives rise to internucleosomal DNA double-strand breaks with fragments of multiples of $180 \mathrm{bp}$, resulting in the typical pattern of DNA ladder that can be detected by electrophoresis on agarose gels. Other changes include loss of the inner mitochondrial transmembrane potential [7] and exposure of the phospholipid phosphatidylserine to the outer cell membrane, which allows phagocytes to detect and engulf these apoptotic cells [8].

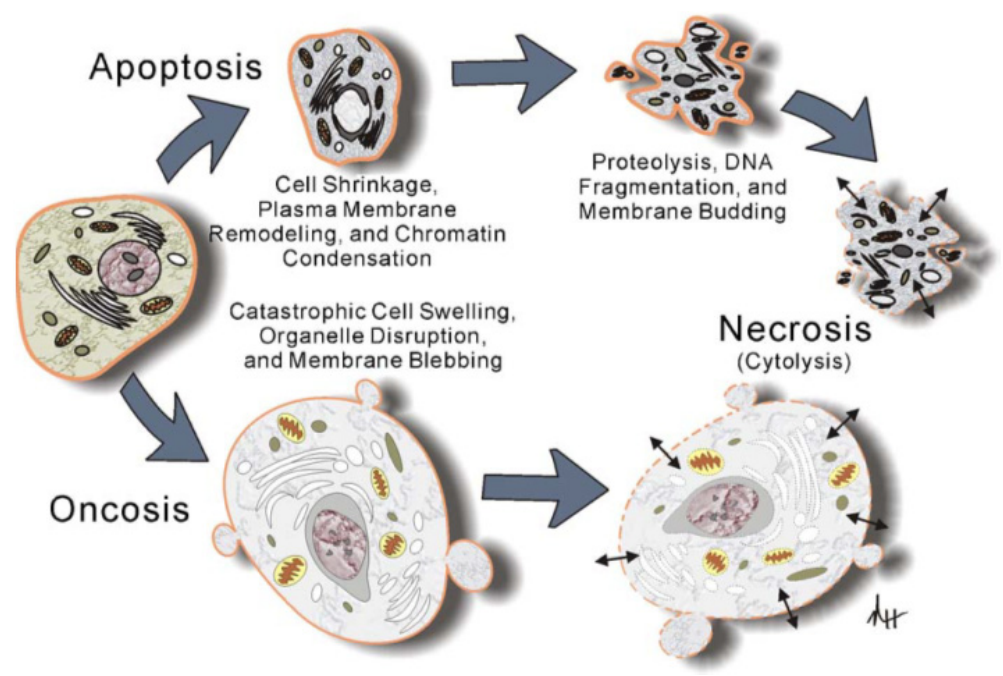

Figure 2. Features of Apoptosis, Oncosis and Necrosis (taken from Hail et al., 2006)

The most distinguishable feature of apoptosis is the formation of apoptotic bodies. On the other hand, oncosis is characterized by cytoplasmic swelling, dilation of organelles and vacuolization and plasma membrane blebbing. The cell will finally die by cytolysis, which is a typical hallmark of necrosis [9]. Apoptotic cells can also lose their plasma membrane and eventually undergo a secondary necrosis. However, this phenomenon has only been observed in vitro. According to Majno and Joris, necrosis is not a type of cell death, but 
rather, it refers to changes subsequent to any type of death. They prefer to use the term oncosis to describe a nonprogrammed or accidental type of cell death characterized by swelling [10]. Moreover, a new modality of cell death has recently emerged, termed necroptosis to indicate a regulated form of necrosis [11].

Apoptosis can be divided into three stages: initiation, integration/decision and execution/degradation [12]. The initiation phase mainly depends upon cell type and apoptotic stimulus. The integration/decision phase consists of the activation of proteases, nucleases and other effector molecules. The execution/degradation phase involves morphological and biochemical changes that are common to all apoptotic mechanisms, regardless of the stimulus that initiated the process. The classical apoptosis is defined as a type of programmed cell death characterized by the activation of zymogens known as caspases, which are cystein-dependent aspartate-directed proteases. Both caspasedependent and caspase-independent cell death mechanisms share multiple characteristics, such as mitochondrial membrane permeabilization (MMP), DNA fragmentation, etc. Hence, (MMP) can commit cells to die even in the absence of caspase activation, by releasing factors such as apoptosis inducing-factor (AIF) or endonuclease G (endo G).

\section{Caspases: Executioners of the apoptotic process}

Caspases are the effector molecules of apoptosis in mammals. They were first discovered mediating programmed cell death during development in the nematode Caenorhabditis elegans [13]. The caspase family is characterized by their specificity for cleaving substrates after aspartic acid residues and for containing cystein in their active centre [14]. There are about fourteen caspases that used to be classified into two families: one involved in inflammation processes and the other taking part in apoptosis. However, some of the nonapoptotic caspases have some apoptotic roles, and conversely, some non-apoptotic caspases can induce pyroptosis [15]. They are synthesized as inactive precursors or zymogens (procaspases) that need to be proteolytically processed to become active. Once a caspase is activated, it can cleave another caspase creating thus an expansive hierarchical activating cascade that serves to amplify the apoptotic signal. Caspase activation is a complex and tightly regulated process. Within the apoptotic group, there are two types of caspases: upstream initiator or apical caspases and downstream effector or executioner caspases. The initiator group consists of caspases $-2,-8,-9$ and -10 and the effector group consists of $-3,-6$ and -7 caspases. Apical but not executioner caspases have long prodomains. Caspase- 9 is considered the initiator of the mitochondrial pathway and caspase- 8 is regarded as the originator of the dead receptor-mediated apoptotic pathway. Effector caspases carry out apoptotic programmes through direct processing of a variety of cellular substrates. The proteolytic cleavage of such substrates brings about a whole plethora of effects within the cell: disassembling of cytoskeleton, cytoplasm scaffolding, nuclear fragmentation as a consequence of laminin degradation, activation of endonucleases that cleave chromatin, inactivation of DNA damage repair proteins (PARP1, Rad9, etc.), phagocyte signalling, loss of cell-to-cell contact, etc. [16-18] 


\begin{tabular}{|c|c|}
\hline Substrate & Funtion \\
\hline $\begin{array}{l}\text { PARP, DSBs, Rad51 and Rad9, DNA- } \\
\text { PKCs and ATM }\end{array}$ & DNA damage repair \\
\hline $\mathrm{C} 1, \mathrm{C} 2$ and $\mathrm{U} 170$ & mRNA processing \\
\hline $\begin{array}{l}\text { Actin, Gas2, FAK, PAK2, Fodrin and } \\
\text { Gelsolin }\end{array}$ & Cellular structure \\
\hline PKC and Akt & Apoptosis and cell cycle \\
\hline Phosphatase $2 \mathrm{~A}$, Raf1 and $\mathrm{Rb}$ & Cell cycle \\
\hline Bid, Bcl-2, Bcl-xL and XIAP & Apoptosis regulation \\
\hline Pro-IL-1 $\beta$ & Cytokine \\
\hline D4-GDP Inhibitor & Rho GTPases regulator \\
\hline Laminin $\mathrm{A} / \mathrm{C}$ and $\mathrm{B}$ and NuMA & Nuclear shape maintenance \\
\hline ACINUS & Regulation of chromatin condensation \\
\hline ICAD & DNA fragmentation \\
\hline Huntingtin & Huntington disease \\
\hline SREBP-1 and SREBP-2 & Sterol regulatory element binding proteins \\
\hline MDM2 & Transcription factor \\
\hline
\end{tabular}

Table 1. Proteins substrates of caspases (Blank and Shiloh 2007; Cohen et al 1997)

Caspase activity can be regulated both in a positive and in a negative manner. Negative caspase regulators are called Inhibitors of Apoptosis Proteins (IAPs) that bind to the catalytic site of caspases neutralizing its activity [19], or targeting them to degradation by ubiquinitation [20,21]. Some examples of IAPs are: XIAP, c-IAP1, c-IAP2, NAIP and survivin. On the other hand, Smac/DIABLO and Omi/HtrA2 act as positive regulators by inactivating IAPs [22].

\section{Extrinsic and intrinsic apoptotic pathways}

There are at least two main well characterized apoptotic routes: the death receptor or extrinsic pathway and the mitochondrial or intrinsic pathway. The extrinsic pathway plays a major role in tissue homeostasis and responds to external cues, coming especially from the immune system, whereas the intrinsic pathway is triggered as a response to various internal insults such as DNA damage, cytosolic calcium overload, starvation, oxidative stress, radiation, cytotoxic agents, etc., and involves mitochondrial destabilization [23,24].

The death receptor pathway is initiated by extracellular stimuli that are recognized by a subgroup of the tumour necrosis factor receptor (TNF-R) family named dead receptors (Fas/CD95/APO-1, TNFR1, TRAIL R1/DR4 and TRAIL R2/DR5). Upon binding of their ligands (FAS, TNF $\alpha$ and TRAIL) these receptors become activated and interact via their death domain with the protein motif Fas-associated death domain (FADD) in adapter proteins, forming the Death inducing signalling complex (DISC), which binds to the prodomain of the initiator caspase- 8 [25]. Thus, caspase- 8 is activated by dimerization, 
which leads to autocatalyisis and consequently activation of executioner caspases $-3,-6$ and 7 [26].

The intrinsic mitochondrial pathway is characterized by the action of B-cell lymphoma (Bcl2 ) proteins. This family consists of proapoptotic and antiapoptotic proteins. The proapoptotic members promote mitochondrial outer membrane permeabilization (MOMP) and the antiapoptotic members counteract this action, so that the balance between these two groups of proteins determines the final outcome [27,28]. If the balance is in favour of the proapoptotic members, the outer mitochondrial membrane is permeabilized through pore formation and cytchrome $\mathrm{c}$ and other proteins such as Smac/DIABLO and Omi/HtrA2 are released to the cytosol. Then, cytochrome $\mathrm{c}$ binds to the adaptor protein Apaf-1 and dATP, forming the apoptosome, a catalytic complex that activates caspase- 9 which in turn activates the executioner caspases.

The extrinsic and intrinsic pathways are interconnected through Bid. In some cases, when DISC formation is low, caspase- 8 activation can induce MOMP through Bid cleavage, which translocates to the mitochondria and induces cytchrome c release, apoptosome formation and engagement of the caspase cascade [29].

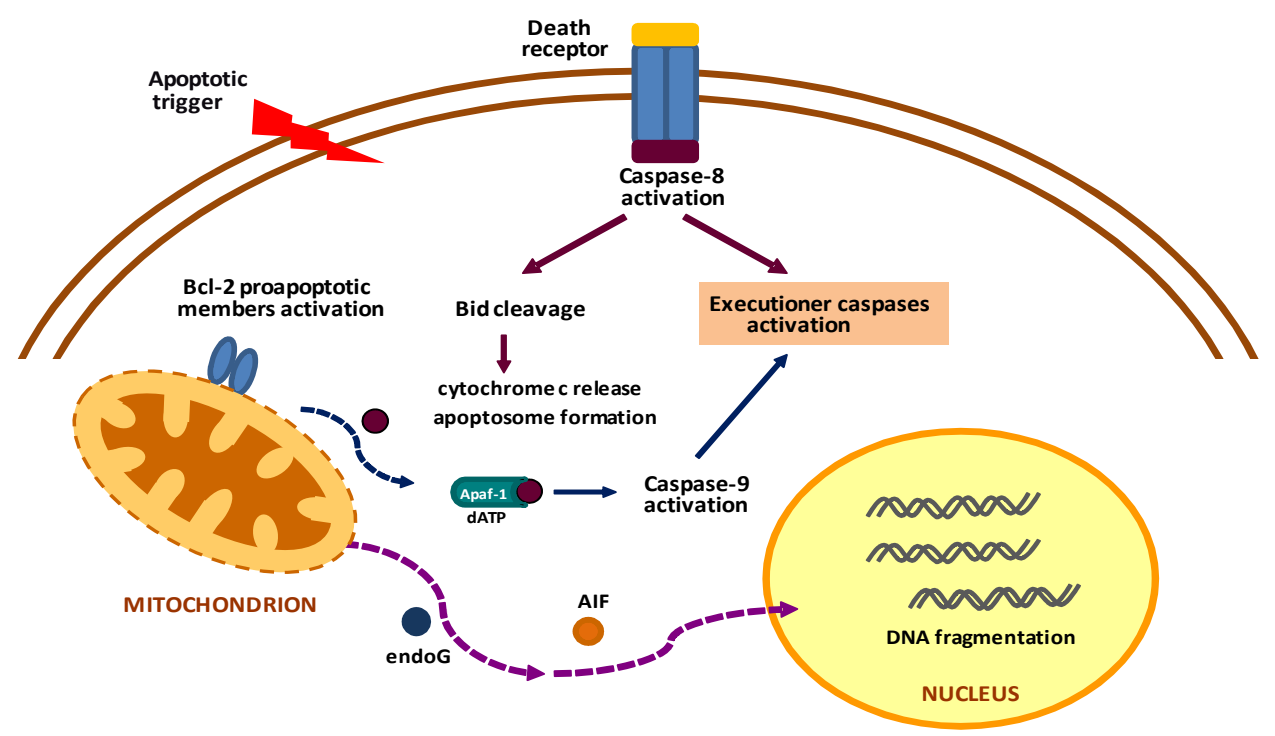

Figure 3. The extrinsic and intrinsic apoptotic pathways.

\section{Death receptors}

Death receptors belong to the TNF-R superfamily of receptors. They participate in proliferation, differentiation, immune response, gene expression, survival and cell death. In 
fact, TNF-R1 and Fas (CD95/APO-1) are involved in apoptotic processes [30]. Death receptors are stimulated by death ligands: TNF; Fas ligand (FasL) and TNF-related apoptosis-inducing ligand (TRAIL). Death receptors contain an intracellular globular interaction domain called death domain (DD). Upon ligand binding, death receptors aggregate forming trimers. As a consequence of this aggregation, they recruit adaptors such as FADD, which interacts with caspase- 8 by virtue of its death effector domain (DED), forming the multi-protein complex known as DISC. However, in some instances, death receptors can oligomerize in the abscence of ligand binding. For example, they can be activated by UV radiation [31]. Fas and TNF-R1 can also recruit RIP (receptor-interacting protein) -associated Ich-1/CED homologous [ICE (interleukin-1 $\beta$-converting enzyme)/CED-3 (cell-death determining 3) homologue 1] protein with death domain (RAIDD) which activates caspase- 2 through a caspase activation and recruitment domain (CARD). In addition, death receptors can participate in caspase-independent mechanisms. For instance, TNF-R1 can activate Extracellular signal-regulated kinase 2 (Erk2) through the mitogenactivated kinase activating death domain (MADD) protein [32]. Fas can bind Death-domain associated protein (Daxx) and activate c-Jun amino-terminal kinase (JNK) [33]. TNF-receptor associated death domain (TRADD) and RIP can activate Nuclear factor kappa-light-chainenhancer of activated B cells (NFkB), triggering a form of regulated necrosis named necroptosis [34].

\section{Role of mitochondria in cell death}

MMP, a crucial event of the intrinsic mitochondrial apoptotic pathway, is considered a "point of no return" in the sequence of events leading to apoptosis. This phenomenon is associated with mitochondrial membrane potential loss $\left(\Delta \Psi_{\mathrm{m}}\right)$ that occurs as a result of assymetrical distribution of protons on both sides of the inner mitochondrial membrane. This irreversible process can take place before, during or after MOMP. The pore formation caused by Bcl-2 proteins induces MOMP, which leads to $\Delta \Psi_{\mathrm{m}}$ dissipation, inhibition of ATP synthesis and $\Delta \Psi_{\mathrm{m}}$-dependent transport activities. Consequently, the respiratory change ceases, causing reactive oxygen species (ROS) generation and release of proteins confined within the inner mitochondrial space [35]. The contribution of the inner mitochondrial permeabilization, however, is controversial. MOMP can also result from the phenomenon called mitochondrial permeability transition that implies the opening of a non-selective pore in the inner mitochondrial membrane known as the mitochondrial permeability transition pore complex [12].

\subsection{Mechanisms of MOMP}

Bax/Bak pore formation. The first proposed mechanism of MOMP is mediated by the Bcl-2 family of proteins that directly act on the outer mitochondrial membrane. This family consists of about 17 members, some of which are proapoptotic and others antiapoptotic. The antiapoptotic members (Bcl-2, Bcl-xL, Bcl-w, Mcl-1, A1, Bcl-B, etc.) contain 3-4 BH domains (Bcl-2 homology regions: $\mathrm{BH}-1, \mathrm{BH}-2, \mathrm{BH}-3$ and $\mathrm{BH}-4$ ) and are named "Bcl-2 like" proteins. 
Among the proapoptotic members, some contain 2-3 BH domains (Bax, Bak, Bok, etc.) and the "BH3-only" proteins (Bid, Bad, Bim, Bik, Bmf, Hrk, Bnip3, Noxa, Puma, Spike, etc.) have the biggest proapoptotic potential. BH-3 only proteins exert their effects either by inhibiting antiapoptotic Bcl-2 like members or by directly activating Bak and Bax. In the first mechanism, "facilitators" such as Bad interact with antiapoptotic Bcl-2 like proteins, dissociating them and creating MMP. In the second mechanism, however, "activators" such as truncated Bid (tBid) activate proapoptotic proteins by stimulating translocation of Bax to the mitochondrial membrane or by activating Bak [36].

The interplay between antiapoptotic and proapoptotic proteins decides the final fate of the damaged cell. Antiapoptotic proteins can be found in the outer mitochondrial membrane, in the cytoplasm or in the Endoplasmic Reticulum (ER). Some propapoptotic members such as Bax or Bid reside in the cytosol, but translocate to the outer membrane upon triggering of a death stimulus, where they oligomerize to form a channel, either with themselves or with membrane anchored-Bak or tBid. The importance of the interactions between proteins and lipids is becoming more evident. In fact, it is now thought that Bak or Bax destabilize lipid bilayers instead of forming pores. BH3-only proteins activity is transcriptionally and posttranslationally regulated. Bid, for instance, is regulated by caspase-8, cathepsins, granzyme B or calpain [37-39]. The proapototic protein Bad in inhibited through phosphorylation by Akt and activated through dephosphorylation by calcineurin [40].

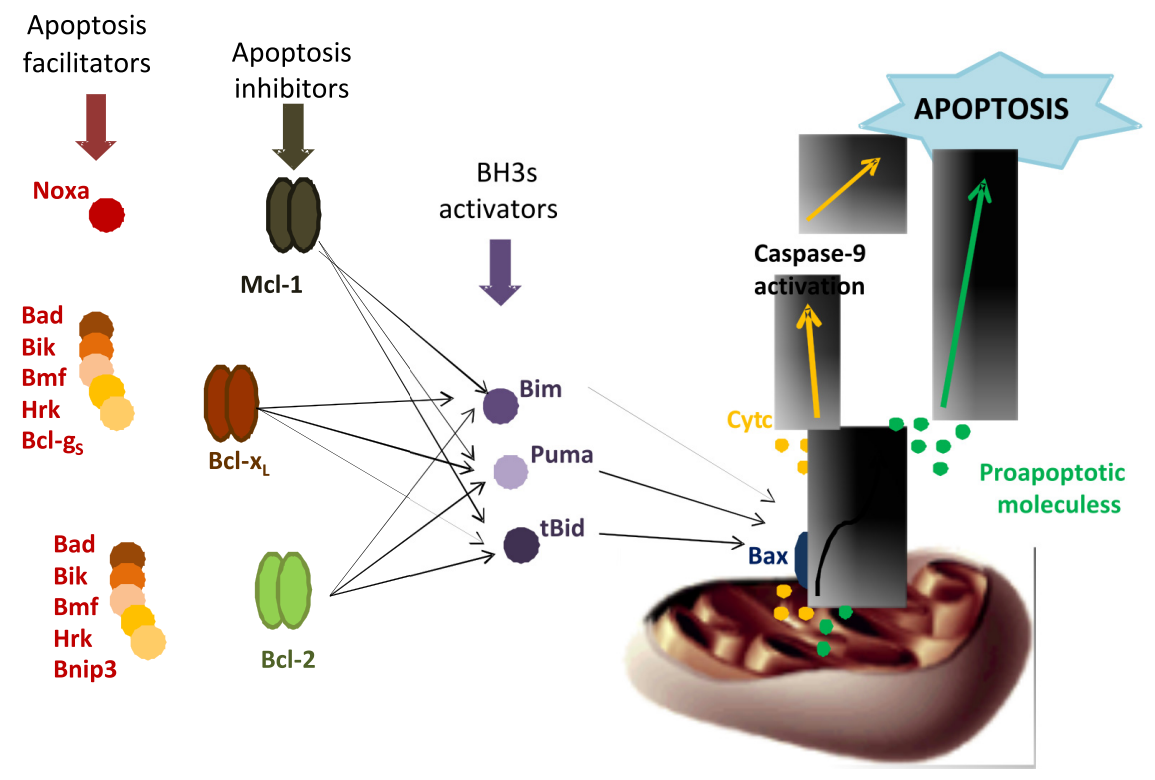

Figure 4. Proposed model of mitochondria membrane permeabilization. Bax/Bak pore formation. Bcl-2 family members regulation.

Permeability transition pore complex. The second proposed mechanism of MOMP is based on the formation of the permeability transition pore (PTP) complex, a high conductance 
channel which allows the influx of water and small solutes. PTP is a multiprotein complex located in the mitochondrial membrane that spans contact sites between the inner and the outer mitochondrial membranes. It is composed of three proteins: the voltage-dependent anion channel (VDAC), which is the most abundant protein of the outer membrane, the soluble matrix protein cyclophilin $\mathrm{D}(\mathrm{CypD})$, and the adenine nuclease translocase (ANT) located in the inner membrane. Other proposed PTP components are: hexokinase, creatine kinase and peripheral benzodiazepine receptor. The requirement of ANT is controversial. Distinct VDAC isoforms may interact with Bcl-2 members in a different manner. PTP opening leads to $\Delta \Psi_{\mathrm{m}}$ dissipation, uncoupling of oxidative phosphorylation, water and ions influx, matrix swelling, outer membrane rupture and release of intermembrane space proteins, such as cytochrome c. $\mathrm{Ca}^{2+}$ favours PTP opening and permeability transitions are regulated by $\Delta \Psi_{\mathrm{m}}, \mathrm{pH}$ of mitochondrial matrix, redox potential, adenine nucleotides and bivalent metallic ions. PTP regulation by Bcl-2 proteins is still a matter of debate. It has been proposed that proapototic members promote pore opening, whereas antiapoptotic proteins favour pore closure [41]. Bcl-2 members can indirectly regulate PTP opening through $\mathrm{Ca}^{2+}$ efflux from the ER. In healthy cells, Bcl-2 or Bcl-XL can be located not only inserted in the mitochondrial outer membrane but also in the ER. Calcium ions exit the ER through inositol phosphate 3 receptors (IP3R), which can be blocked upon Bcl-2 binding. The proapoptotic members Bax and Bak induce $\mathrm{Ca}^{2+}$ movement from the ER to the mitochondrion [42]. However, $\mathrm{Ca}^{2+}$ interchange through PTP can be regulated by proapoptotic tBid $[43,44]$.

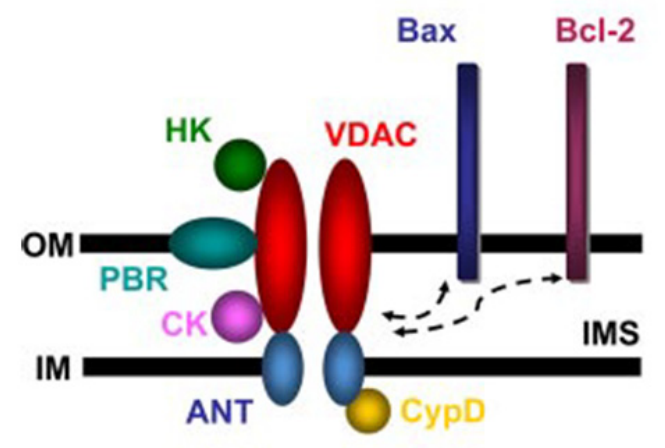

Figure 5. Proposed model of mitochondrial membrane permeabilization. Permeability transition pore complex. OM: outer membrane. IMS: intermembrane space. IM: inner membrane. VDAC: voltagedependent anion channel. HK: hexokinase. PBR: peripheral benzodiazepine receptor. CK: creatine kinase. ANT: adenine nuclease translocase. CypD: cyclophilin D (modified from Kroemer et al. 2007).

The rise of mitochondrial matrix $\mathrm{Ca}^{2+}$ induces oxidative metabolism. However, upon apoptotic stimulus, $\mathrm{Ca}^{2+}$ can cause PTP opening, which can be transient and provide a fast calcium release mechanism, or persistent, giving rise to outer membrane rupture and release of apoptotic factors. Additionally, a different channel has been identified in the mitochondrion, composed of ceramide, a lipid that can form hydrogen bonds giving rise to ceramide structures that form channels which allow the efflux of proteins up to $60 \mathrm{kDa}$ [42]. 


\subsection{Cell death effectors released from mitochondria}

The release of proteins from the intermembrane space and the loss of membrane-associated mitochondrial functions lead to cell death. Albeit is not clear the mechanism, mitochondrial destabilization provokes release of factors that mediate in caspase-dependent and independent pathways.

Cytochrome $\mathrm{c}$ is a protein localized in the intermembrane mitochondrial space where it participates in the electron transport between complex III and IV of the mitochondrial respiratory chain. As already mentioned, cytochrome $\mathrm{c}$ is involved in the apoptosome formation and caspase cascade activation [45]. Cytochrome c release is a crucial step in the intrinsic apoptotic pathway.

Smac/DIABLO means Second mitochondrial activator of caspases or Direct IAP Binding protein with LOw pI. This $29 \mathrm{kDa}$ protein is also localized in the intermembrane space and is released to the cytosol upon activation by certain apoptotic stimuli, where it binds IAPs, preventing their function and favouring caspase activation.

Omi/HtrA2 functions in a similar way to Smac/Diablo. This $36 \mathrm{kDa}$ protein belongs to a highly conserved protein family. In healthy cells, Omi/HtraA2 is located in the intermembrane space. Upon apoptotic triggering (TRAIL, UV radiation, staurosporine, etc.) is released to the cytosol where it binds and inactivates IAPS promoting caspase activation.

In addition, to the caspase-dependent effectors already mentioned, other caspaseindependent proteins can be activated:

AIF stands for Apoptosis Inducing Factor. AIF is a $57 \mathrm{kDa}$ flavoprotein localized in the intermembrane space whose aminoacid sequence resembles ferrodoxin. AIF is expressed as a $67 \mathrm{kDa}$ precursor that possesses two mitochondrial localization sequences in its aminoterminal end. Once in the mitochondria, AIF precursor is cleaved giving rise to the mature protein that is believed to have an oxidoreductase function based on its FAD domain, playing an important physiological role in oxidative phosphorylation. AIF translocates to the nucleus in response to apoptotic stimuli where it induces chromatin condensation and large-scale $(50 \mathrm{Kbp})$ DNA fragmentation by an unknown mechanism, leading to apoptosis in a caspase-independent fashion. It has been recently suggested that Steroid receptor coactivator-interactive protein prevents AIF release from the mitochondria [46]. Conversely, calcium-activated calpain promotes AIF release from the mitochondria [47] and poly-ADPribose-plymerase 1 (PARP-1) activity is necessary for AIF translocation to the nucleus [48].

Endo $G$ or Endonuclease $G$ also participates in caspase-independent cell demise mechanisms. It belongs to a family of $\mathrm{Mg}^{2+}$-dependent endonucleases. Endo $\mathrm{G}$ is a $30 \mathrm{kDa}$ mitochondrial protein that, like AIF, is synthesized as a precursor form and its mitochondrial localization sequence is cleaved when the protein reaches the intermembrane space. Endo G is released from the mitochondria upon certain apoptotic stimuli such as UV radiation or anti-Fas antibodies, and it translocates to the nucleus, where it cleaves chromatin DNA into nucleosomal fragments. Endo G cooperates with exonucleases and 
DNase I in order to facilitate DNA processing. Endo G nuclease activity has been observed even in the presence of caspase inhibitors. Therefore, similarly to AIF, Endo G participates in caspase-independent cell death mechanisms. The physiological role of Endo G, however, needs to be established.

Besides its function as IAP inhibitor, Omi/HtrA2 has been implicated in caspaseindependent cell death mechanisms by virtue of its serine protease activity. This effector molecule cleaves proteins such as ped/pea-15 [49], HAX-1 [50], or RIP-1 [51]. However, the exact mechanism as to how this occurs is still unknown.

AIF and Endo G activity together with Omi/HtrA2 serine protease activity are considered responsible for the recently called caspase-independent intrinsic apoptosis [11].

\subsection{Afferent signals from other organelles}

Mitochondria play a central role in programmed cell death pathways and integrate different signals coming from other organelles, being MMP, a point of no return, as already mentioned.

\subsubsection{Nuclear DNA damage}

The tumour suppressor p53 mediates DNA damage response, either by stimulating DNA damage response or by inducing apoptosis. As a transcription factor, p53 transactivates Bcl2 proteins (Bad, Bid, Puma and Noxa) [52], which induce MMP and release of proteins from the intermembrane space [12]. After DNA damage, p53 can also induce the expression of p53-induced protein with a death domain (PIDD), which activates nuclear caspase-2. PIDD associates with RAIDD, forming a signalling platform known as the PIDDosome [53]. The PIDDosome can activate caspase- 2 and the transcription factor NFkB in response to DNA damage [54]. Caspase-2 acts upstream of the mitochondria by inducing Bid cleavage, Bax translocation and cytochrome c release. The role of caspase-2 in apoptosis, however, is controversial. It is now thought that caspase-2 functions as a tumour suppressor gene regulating the cell cycle machinery [55]. p53 may also induce apoptosis by transcriptionindependent mechanisms, for instance, by directly interacting with Bak, Bax, Bcl-2 and Bcl$X_{\mathrm{L}}$ at the outer mitochondrial membrane [56]. The activity of p53 can be promoted by glycogen synthase kinase $3 \beta$ (GSK3 $\beta$ ) binding both in the nucleus and in the mitochondria, which in turns promotes cytochrome c release and caspase-3 activation [57].

\subsubsection{Endoplasmic reticulum: Unfolded protein response}

The ER has primordial roles in normal physiological and survival processes. These include intracellular calcium homeostasis, protein secretion and lipid biosynthesis [58]. Apoptosis can be initiated as a consequence of stress in the ER. This stress condition can be caused by calcium homeostasis alteration, glucose deprivation, hypoxia, low redox potential, excessive protein synthesis or defective protein secretion. These insults can cause accumulation of 
unfolded proteins in the lumen of the ER, triggering an evolutionary conserved signalling pathway known as the Unfolded Protein Response (UPR) which can culminate in cell death. UPR consists of global protein synthesis reduction, synthesis induction of chaperones and other proteins related to protein folding and retro-translocation of misfolded or unfolded proteins from the ER to the cytosol, where they will be degraded by the proteasome [59]. When the ER stress is sustained and ER function cannot be restored, UPR activates a specific apoptotic pathway. Caspase-12, which is localized in the ER, is activated by calciumdependent proteases known as calpains [60]. Once activated, caspase-12 activates caspase- 9 without apoptosome intervention [61,62]. It has been postulated that ER stress can also activate caspase-8, which induces cytochrome c release through Bid processing [29,63]. In addition, ER stress can also initiate autophagy, a different type of cell death.

\subsubsection{Lysosomes}

Lysosomes are organelles that contain acidic hydrolases such as cathepsins. Rupture of lysosomes release cathepsins to the cytosol, where they can trigger apoptosis or necrosis. Cystatins, on the other hand, are cytosolic proteins that act as negative regulators of cathepsins when they are translocated from lysosomes to the cytosol. Apoptosis initiated in lysosomes follows a mitochondrion-dependent pathway associated to caspase activation. However, it has been shown that cathepsin D activates Bax and AIF release, triggering a caspase-independent apoptotic pathway [37]. Furthermore, some cathepsins induce Bid cleavage [38], interaction with Bcl-2 proteins and permeabilization of the mitochondrial membrane [64]. In addition, cathepsins can alter mitochondria functions by cleaving subunits of the oxidative phosphorylation complexes, inducing ROS generation [12]. Lysosomes are essentially involved in autophagic cell death mechanisms.

\subsubsection{Cytosol}

Several signals coming from the cytosol can induce MMP. These include: metabolites such as glucose 6-phospate and palmitate, ROS and activation of certain kinases: GSK3 $\beta$, protein kinase $\mathrm{C}(\mathrm{PKC}) \delta,[65]$ and members of the JNK signalling pathway $[38,66]$. On the other hand, other molecules inactivate PTP and protect mitochondrial membrane from permeabilization, inhibiting apoptosis. These include: metabolites (ATP, glucose, NADH, UTP, etc.), antiapoptotic Bcl-2 family members, antioxidant enzymes such as glutathiones $S$ transferase and prosurvival kinases such as Akt. In this sense, Akt can inhibit apoptosis by several mechanisms: activation of NFkB [67], inactivation of GSK3 $\beta$ and caspases and through hexokinase II-dependent mechanisms [12].

\subsubsection{Cytoskeleton}

The cytoskeleton is composed of microtubules, microfilaments and intermediate filaments that play important roles in cell motility, polarity, attachment, shape maintenance, etc. Adherent cells can undergo a specific type of caspase-dependent cell death called anoikis 
when they become detached from the extracellular matrix or neighbouring cells $[68,69]$. Besides its well-established role in mitosis, cytoskeleton components can modulate mitochondria. For example, microtubules sequester BH3-only proteins Bim and Bmf, which interact with dynein [70]. Gelsolin has anti-apoptotic effect by closing the VDAC channel [71]. Actin can also modulate VDAC closure [69,72].

\section{Parp proteolysis as an indicator of cell death}

Poly-ADP-Ribose Polymerase (PARP) is a family of 16 nuclear enzymes, among which, the best characterized is PARP-1. PARPs have several functions in cell proliferation, cell death, DNA recombination and DNA repair. PARP-1 is a $116 \mathrm{kDa}$ nuclear protein involved in DNA repair mechanisms. PARP synthesis is activated when DNA is fragmented in the presence of nuclear poly-ADP ribosylated proteins. In an early apoptotic stage, caspases cleave PARP resulting in an $89 \mathrm{kDa}$ and a $24 \mathrm{kDa}$ fragments [73]. The smaller fragment irreversibly binds DNA fragment ends, impeding the access of DNA repair enzymes. Hence, PARP proteolysis facilitates nuclear disorganization and ensures irreversibility of the apoptotic process [74]. PARP cleaves also takes place during necrosis. However, the fragments obtained are of different size [75]. A role of PARP cleavage in autophagy induced by DNA damage has been recently suggested [76]. Parthanatos is a particular case of regulated necrosis in which PARP activation plays an important role. PAR polymer, the product of PARP-1 activation, translocates to the mitochondria and induces AIF release. Subsequently, AIF translocates to the nucleus and provokes chromatin condensation and DNA fragmentation [77]. Necroptosis or regulated necrosis also involves PARP activation [78]. Therefore, PARP can participate in different types of cell death and it is not exclusive of apoptosis, as previously thought.

\section{Autophagy}

Autophagy is a self-digestive physiological process that occurs in all eukaryotic cells, during which long-lived proteins and organelles are degraded by lysosomes to maintain cellular homeostasis [79]. To date, at least three types of autophagic pathways have been described: macroautophagy (simply called "autophagy"), microautophagy and Chaperone-Mediated Autophagy (CMA). These forms differ in the mode the cargo is delivered to the lysosome.

Macroautophagy is a dynamic process in which portions of the cellular cytoplasm and organelles are sequestered in a double-membrane bound vesicle called autophagosome, which then fuses with the lysosome [80,81]. Microautophagy involves the sequestering by the lysosome itself of part of the cytoplasm. During microautophagy, the membrane of the lysosome invaginates, and then pinches off to form an internal vacuole that contains material derived from the cytoplasm [82]. The notable difference between macroautophagy and microautophagy is that in the latter, part of the cytoplasm is directly taken up into the lysosome. Both macroautophagy and microautophagy are basically nonselective degradation pathways in which bulk cytoplasm is randomly sequestered. However, in some 
cases, autophagy can selectively eliminate some organelles, such as damaged peroxisomes, mitochondria or ER. In contrast, CMA does not involve vesicular traffic and is specific for the degradation of proteins. During this process, proteins are delivered to lysosomes with the help of molecular chaperones and a lysosomal receptor. Cytosolic proteins with a specific peptide sequence motif ("KFERQ" motif) are recognized by a complex of molecular chaperones (Hsc70) and then bind to a lysosomal receptor called lysosome associated membrane protein (LAMP) type 2a [83].

Macroautophagy (hereafter referred to as autophagy) is the most studied and prevalent form of autophagy in cells. This process begins with the formation of a " $\mathrm{C}$ " shaped doublemembrane structure in the cytosol, called "omegasome", which is formed from the ER (Initiation phase). Following this, the omegasome grows to form the "isolation membrane", which elongates to engulf cytoplasmic components (Elongation phase). Then, the "isolation membrane" curves and closes to form a vacuole called the autophagosome (Maturation phase). As a result, portions of the cell cytoplasm and some organelles are sequestered in this vacuole. Finally, the outer membrane of the autophagosome fuses with the lysosomal membrane and the inner membrane (the autophagic body) carrying the cytosolic constituents enters the lysosome. The autophagic body is degraded in the lysosome by hydrolases and the resulting free amino acids and macromolecules are transported back into the cytosol for reuse [84]. In this way, autophagy contributes to the maintenance of the cellular energy homeostasis, to the clearance of damaged organelles and to adaptation to environmental stresses [85]. Accordingly, autophagy defects have been linked to a wide range of human pathologies, including cancer.

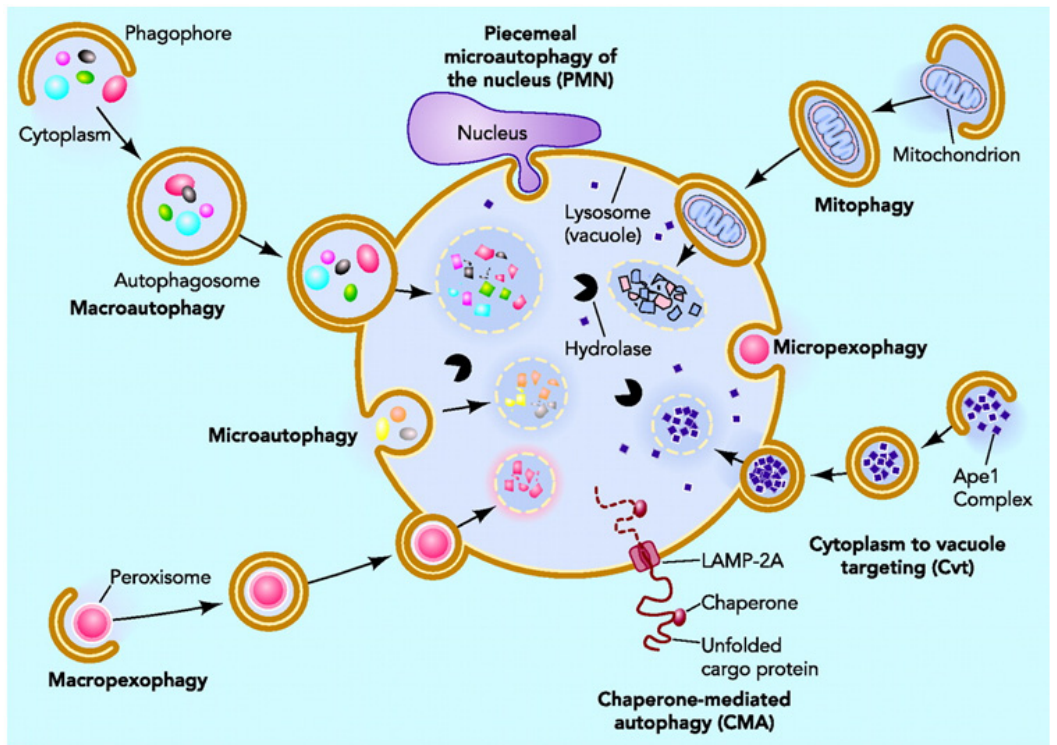

Figure 6. Autophagy. Three different forms of autophagy are depicted: Macroautophagy, Microautophagy and Chaperone-mediated autophagy (CMA) (taken from Yen and Klionsky, 2008). 


\section{Mitotic catastrophe}

The cell death process that takes place when mitosis cannot be completed is called mitotic catastrophe. This phenomenon is triggered as a consequence of perturbations of the mitotic machinery that governs appropriate chromosome segregation. The main hallmark of mitotic catastrophe is the enlarged cell size accompanied by multinucleation [5]. Other features are chromatin condensation, DNA degradation, MMP, cyrochrome c release from the mitochondria and caspase activation [86]. Some types of mitotic catastrophe, however, take place without intervention of caspases, what has been named caspase-independent mitotic death [87]. Mitotic catastrophe results form the combination of deficient checkpoints (DNA and mitotic spindle) and DNA damage. Cells that evade the mitotic checkpoint and do not undergo apoptosis are prone to generate aneuploidy. Therefore, mitotic catastrophe is conceived as a device to avoid genomic instability. The players that take part in mitotic catastrophe are: cell cycle-dependent kinases (Cdk1, Aurora, Plk), cell cycle-check points proteins (Chk2, p53, p73), survivin, $\mathrm{MCl}-2$, Blc-2 proteins, caspase-2, etc. [86]. Mitotic catastrophe is a poorly defined molecular signalling pathway that precedes apoptosis, necrosis or senescence [88].
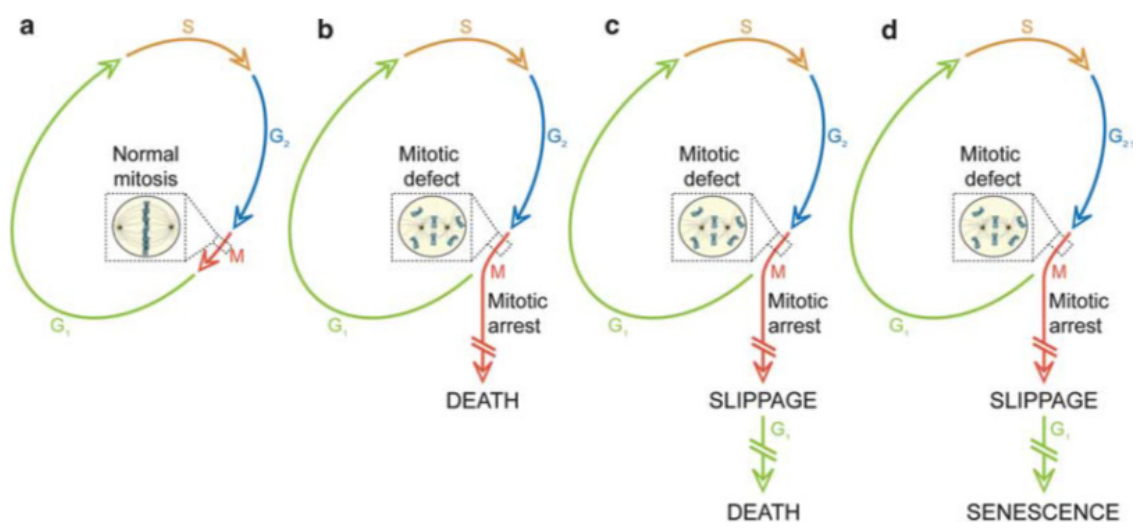

Figure 7. Mitotic catastrophe. a) In the absence of perturbations cells progress normally. A mitotic defect is detected and: b) cells die without exiting mitosis, c) cells undergo mitotic arrest, exit mitosis (mitotic slippage), reach the subsequent $\mathrm{G}_{1}$ and die or $\mathbf{d}$ ) undergo senescence (taken from Galluzzi et al. 2012).

\section{Necroptosis}

Necrosis is characterized by plasma membrane permeabilization, swelling and rupture. Necrosis can be accompanied in many instances by release of lysosomal hydrolases. Recently, a novel form of regulated necrosis has emerged and has been named necroptosis [78]. This cell death modality presents morphological features of necrosis but is regulated by signalling pathways and catabolic mechanisms. The most studied necroptotic pathway is mediated by the death receptor TNFR1 and inhibited by necrostatin-1. Upon TNF binding, TNFR1 undergoes a conformational change and recruits TRADD, TRARF2, cIAP1, cIAP2 
and RIP1 to form complex I. RIP1 is polyubiquinated by cIPA1 and CIAP2 and activates the I Kappa B kinase (IKK) complex, triggering NFkB activation. RIP1 can be deubiquitinated by cylindromatosis D (CYLD) and together with RIP3 forms the complex II which also contains TRADD, FADD, and caspase-8. Subsequently, caspase-8 cleavage will induce apoptosis, whereas caspase- 8 inhibition by caspase inhibitors (zVAD-fmk) for example, will favour necroptosis [89]. A novel death regulation platform named ripoptosome has recently been described. Unlike complex II, the ripoptosome forms independently of death receptors, is activated by genotoxic stress or IAP antagonists and is tightly regulated by IAPs (ciAP1, cIAP2, xIAP) or cellular FLICE-like inhibitory protein (FLIP), a catalytically inactive homologue of caspase- 8 [78,90,91]. The executioner mechanisms of necroptosis are unclear. However, in some cases the necroptotic process involves ROS generation, lysosomal membrane permeabilization, AIF release from the mitochondria and PARP activation. When caspase activation is not involved, necroptosis is associated with formation of autophagic vesicles [92,93].

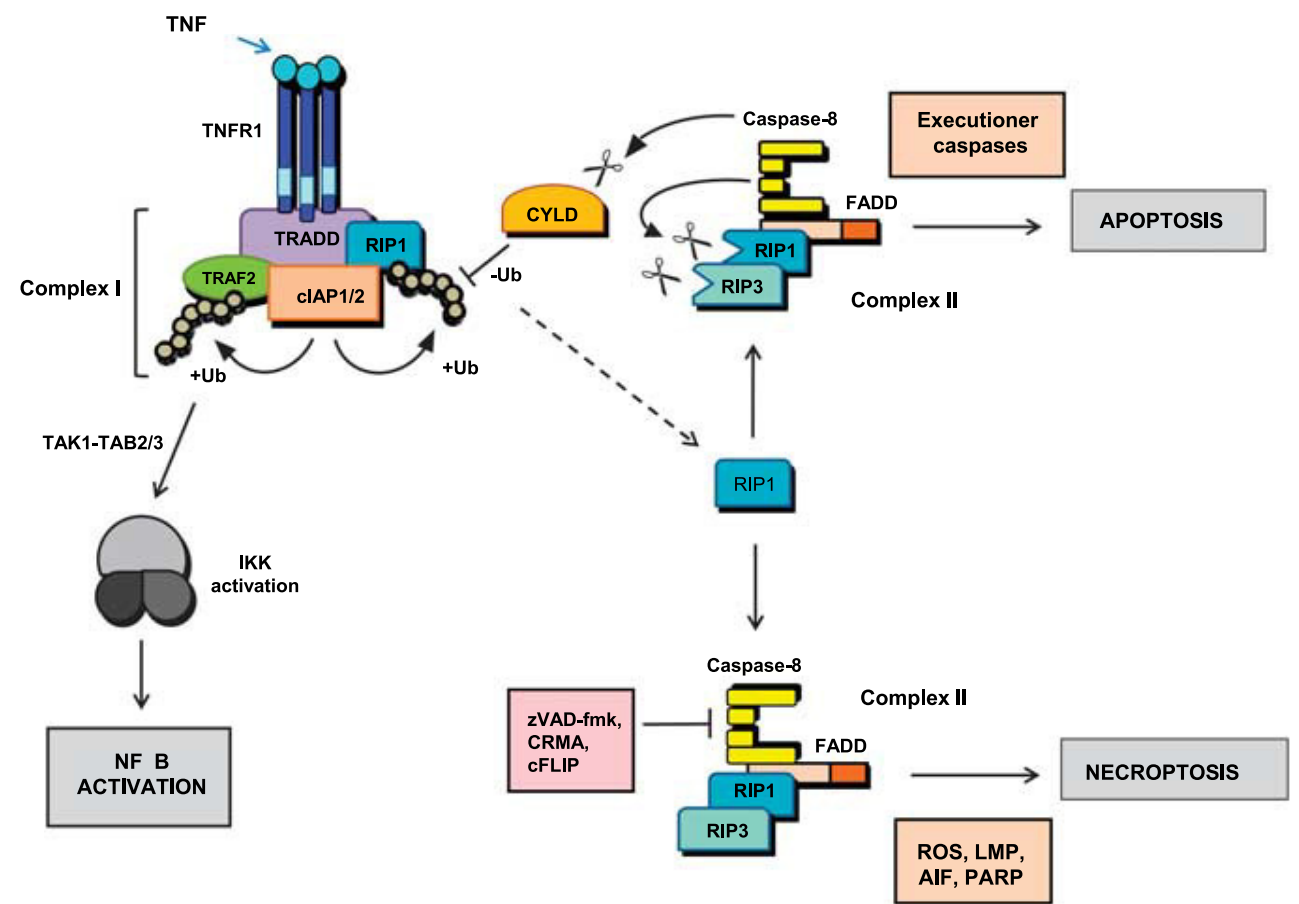

Figure 8. TNFR1-mediated apoptosis and necroptosis (taken from Long and Ryan 2012).

\section{Apoptosis, chemoresistance and cancer}

So far, we have reviewed generalities of different modalities of cell death that can take place after various pathologies: inflammation, stroke, ischemic injury, neurodegenerative disorders, viral infection, neoplasia, etc. The implication of apoptosis in cancer was initially 
observed as the type of cell death occurring in untreated tumours and in tumour regression after radiotherapy [4]. The oncogenic process requires accumulation of diverse alterations within a cell that disrupt its normal homeostasis of cell death and growth. It is well established that excessive proliferation is not only due to oncogene activation but also to failure of the pathways controlling programmed cell death mechanisms [94]. A malignant cell can be protected from cell demise though expression and/or activation of antiapoptotic factors (acting as oncogenes) or through inactivation of antiapoptotic factors (acting as tumour suppressor genes). Evasion of apoptosis is a hallmark of cancer [95]. Dysregulation of apoptotic pathways renders cells resistant to antitumour strategies since the final outcome of radio and chemotherapy is frequently apoptosis of cancer cells. Therefore, resistance to cell death- in particular apoptotic cell death- is an important aspect of carcinogenesis, as it confers resistance to anticancer agents [96]. In many tumours, chemoresistance acquisition is due to upregulation or modification of key elements of apoptosis control, such as Bcl-2, Bcl- $X_{\mathrm{L}}$ and IAP family members [36]. Other mechanisms are characterized by inactivating mutations in proapoptotic proteins, such as p53.

Bcl-2. The first apoptotic gene related to neoplasia was the apoptotic inhibitor $b c l-2$. Therefore, Bcl-2 overexpression can contribute to tumour cell survival. Indeed, it was discovered at the breakpoint of the $t(14 ; 18)$ chromosomal translocation occurring in follicular lymphomas and leukemias [97,98]. Bcl-2 is the first oncogene that acts by inhibiting cell death instead of stimulating cell proliferation. In this respect, it was shown to cooperate with myc in immortalization of lymphoid cells [99] and in lymphomagenesis in transgenic mice [100]. Furthermore, it has been shown that Bcl-2 overexpression can confer multidrug resistance (MDR) phenotype and evasion of apoptosis to tumour cells exposed to serum deprivation, certain toxins or chemotherapeutic agents [101]. Mcl-1 and Bcl- $\mathrm{X}_{\mathrm{L}}$ have been shown to play important roles in tumourigenesis as well. Bcl-2 overexpression can also be the result of gene amplification or reduced expression of micro RNAs (miRNAs) in cancer cells [102].

BH3-only proteins. Loss or suppression of proaptotic proteins is frequent in cancer. Bax frameshift mutations appear in $50 \%$ of colon carcinomas with DNA mismatch repair defects [103]. In addition, $17 \%$ of mantel cell lymphoma has homozygous Bim deletions [104], Bok and Puma suffer allelic deletions [105], and Bim and Puma are silenced by hypermethylationin Burkitt lymphoma [106,107]. Bim expression can also by silenced by miRNAs in several types of cancers [102]. Some BH-3 only proteins (Bim, Puma and Bmf) are necessary to initiate apoptosis in response to certain antineoplasic drugs [101].

XIAP. The X-linked inhibitor factor of apoptosis (XIAP) belongs to the IAP protein family. XIAP can render chemoresistance to cancer cells by inactivating caspases. XIAP overexpression is frequent in several tumour types [108]. Since XIAP is the only protein capable of inactivating both initiator and executioner caspases, it has become a putative biomarker of chemoresistance. It is the only IAP member capable of blocking active caspases [109]. However, XIAP has other roles in malignant transformation apart from preventing apoptosis. XIAP is involved in NFkB, MAPK and ubiquitin-proteasome pathways [108]. 
Survivin. This protein is a member of the IAP family that inhibits apoptosis by inactivating caspases [110] and stimulates DNA repair upon binding to DNA-PK in glioblastoma cell lines [111]. In addition, survivin plays a role in regulation of the mitotic checkpoint. Survivin expression is deregulated in cancer through several mechanisms: amplification of the locus on chromosome 17q25 [112], exon demethylation [113], or increased promoter activity [114]. Overall, survivin overexpression is an unfavourable prognostic marker and correlates with poor prognosis [110]. It is also involved in angiogenesis [115], tumour progression and chemoresistance. It has been shown that survivin inhibition sensitizes tumour cells to paclitaxel, cisplatin, etoposide, gamma radiation and immunotherapy [116].

p53. Inactivating mutations in the tumour suppressor p53 account for about 50\% of human tumours and are associated with poor prognosis. One role of p53 is the regulation of cell cycle through the DNA damage response. Many chemotherapeutic agents cause DNA damage and activate p53. As a result, the cdk inhibitor p21 can be transcriptionally activated causing cell cycle arrest or Bax can be activated by translocation to the mitochondria inducing apoptosis [56]. When p53 is not mutated, cells showing DNA damage induced by genotoxic stress that cannot be repaired during cell cycle arrest, are induced to apoptosis through p53 activation of the mitochondrial pathway, mostly increasing transcription of the BH-3-only proteins, Bid, Noxa and Puma [52]. In addition, p53 can activate genes of the extrinsic pathway: TRAIL-R2 (DR5) and Fas (CD95/Apo-1) [117].

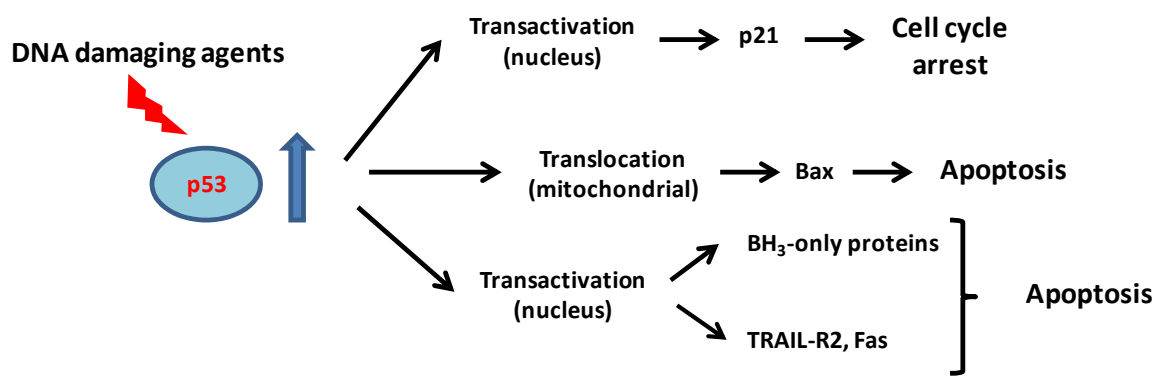

Figure 9. Transcription-dependent and independent effects of p53 activation

\subsection{Defective checkpoints}

p53 and the DNA damage response. DNA damaging agents can induce different types of lesions that culminate in cell death. DNA damage is detected by sensors within the cell that relay a signal causing cell cycle arrest and DNA repair or apoptosis. These networks of genome surveillance are known as replication checkpoints. When DNA damage is low the lesions can be repaired by several mechanisms. On the other hand, when the DNA damage is high or persistent, the cell undergoes apoptosis [118]. For example, as a response to genotoxic insults, p53 is phosphorylated by Checkpoint kinase 1 (Chk1) and Checkpoint kinase 2 (Chk2) and cannot be ubiquinated by $\mathrm{mdm} 2$ and becomes stabilized. Consequently, p21 is activated and cells are arrested either in the $\mathrm{G}_{1}$ or the $\mathrm{G}_{2}$ phase of the cell cycle. Conversely, if p21 is absent, apoptosis prevails. Therefore, p21 is critical in maintaining the 
balance between cell cycle arrest and apoptosis. The frequent loss of p53 in cancer enhances its ability to survive after DNA damage and evade apoptosis. When p53 is mutated, the response to DNA damage depends on mechanisms regulated by Ataxia telangiectasia mutated (ATM) and Ataxia telangiectasia and Rad3 related (ATR) independent of p53, which regulate Chk1 or Chk2 [119]. These kinases in turn activate NFkB, Akt and survivin [120].

Cell cycle checkpoints. Checkpoints are mechanisms that respond to internal or external stress

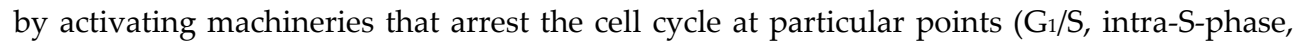
$\mathrm{G}_{2} / \mathrm{M}$, or mitotic spindle). Many tumour suppressor genes are components of DNA damage or cell cycle checkpoints: p53, Retinoblastoma (Rb), ATM, p16, BRCA1/2, etc. The frequency of tumour suppressor loss in cancer cells provides an advantage to their growth. The $\mathrm{G}_{1}$ checkpoint is controlled by $\mathrm{Rb}$, which in turn, is phosphorylated by cdk's. One cdk inhibitor is p16. Both $\mathrm{Rb}$ and p16 are frequently mutated in diverse types of cancer. The mitotic checkpoint utilizes genes (Mad, Bub, Aurora kinases) to detect spindle defects. When the cell is not able to surpass the damage, it undergoes mitotic catastrophe. In addition, loss of checkpoint controls increases genomic stability, providing cancer cells with adaptive or evolutionary advantages [121].

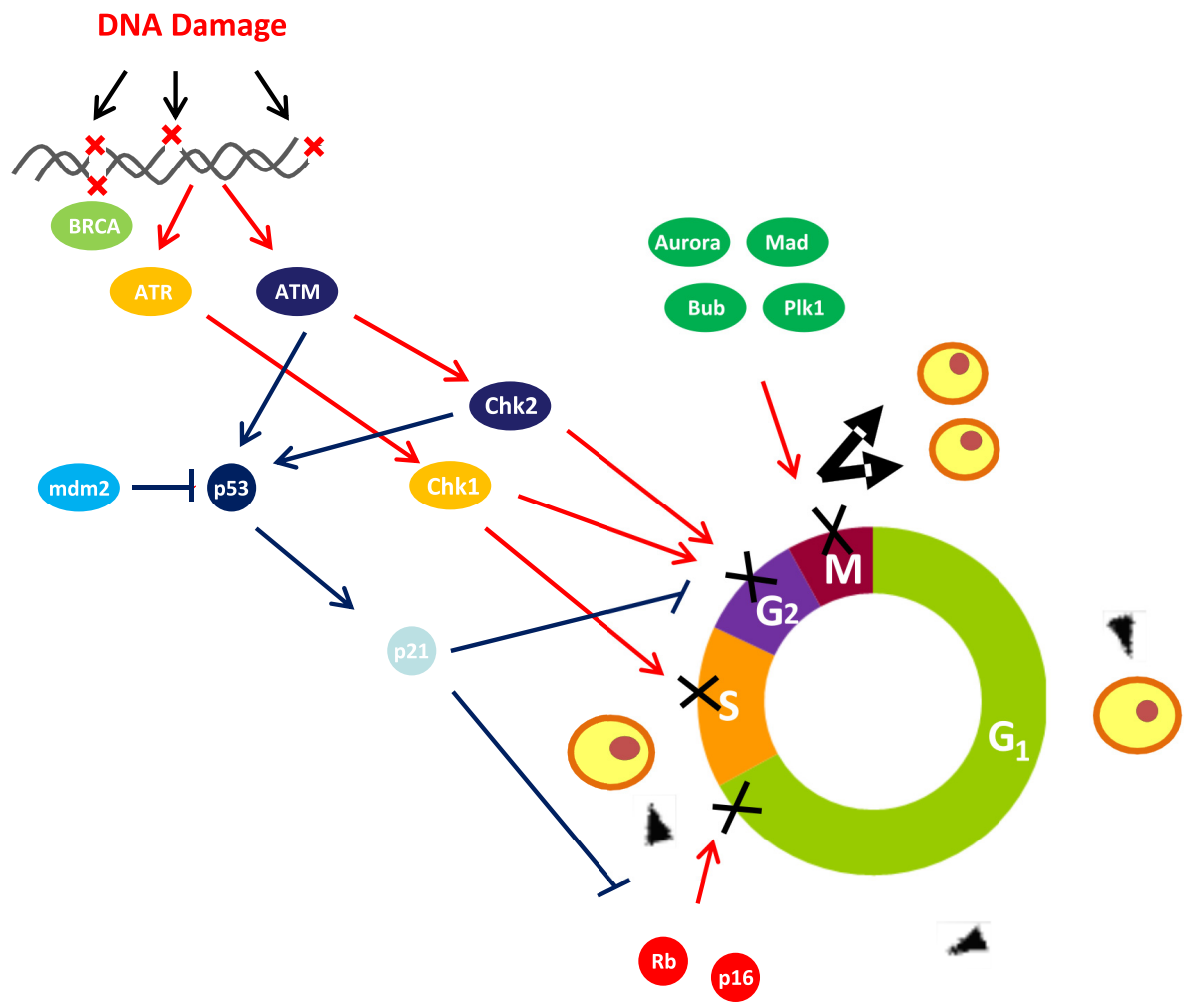

Figure 10. DNA damage and cell cycle checkpoints 


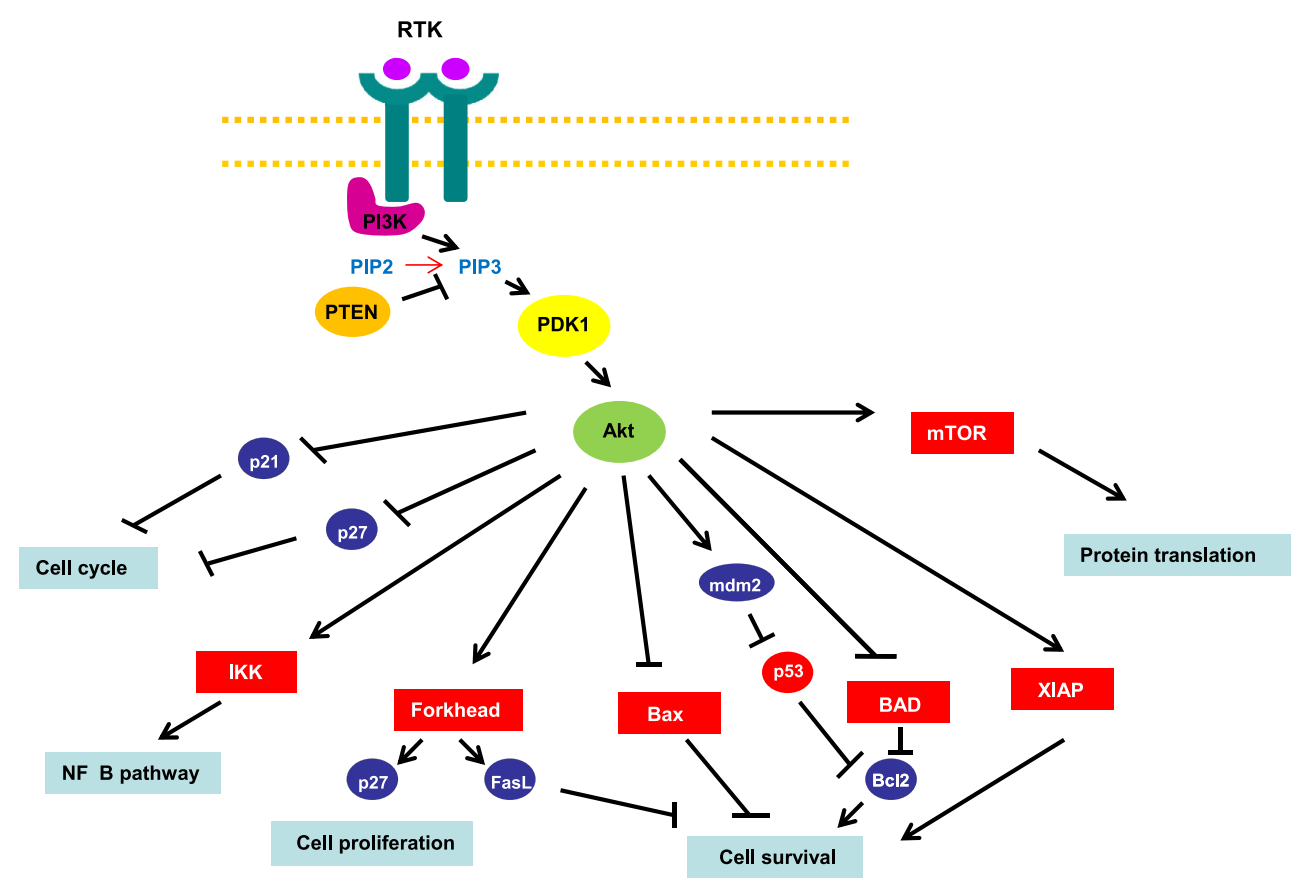

Figure 11. Akt signalling pathway

Akt. Classically, the phosphoinositide-3-kinase (PI3K)-Akt-mTOR pathway is described as a key signal transduction cascade that integrates signals from growth factors and nutrients to regulate cell growth and proliferation [122]. Following growth factor binding to cell surface receptors, $\mathrm{PI} 3 \mathrm{~K}$ is activated and phosphorylates phosphatidylinositol-4,5-biphosphate ( $\left.\mathrm{PIP}_{2}\right)$ to generate the second messenger phosphatidylinositol-3,4,5-trisphosphate ( $\left.\mathrm{PIP}_{3}\right)$. This process can be inhibited by the tumour suppressor protein phosphatase and tensin homolog (PTEN), which dephosphorylates PIP3 and terminates PI3K signalling. Then, the accumulated PIP3 recruits PDK1 and Akt through their Pleckstrin homology domains, and Akt is activated [123]. Akt recognizes and phosphorylates a consensus sequence that is present in many proteins. These substrates control key cellular processes such as apoptosis, cell cycle progression, transcription, and translation, all of which are critical events in cancer [124]. The Akt signal transduction pathway is probably the best survival pathway characterized. Moreover, Akt is constitutively activated in several malignant tumours, such as prostate, breast, ovary, lung and liver carcinomas [125]. Akt suppresses apoptosis through different mechanisms, including phosphorylation of forkhead transcription factors, which regulate proapoptotic proteins such as Bim and Fas ligand. The phosphorylated forkhead proteins are trapped in the cytosol and cannot enter the nucleus. Akt also phosphorylates and inactivates several proapoptotic proteins like Bad and caspase-9. Importantly, it activates IKK inducing the transcription factor $N F-\kappa B$, leading to transcription of several antiapoptotic proteins such as Bcl-xL, and XIAP [96,126]. Akt also 
prevents the nuclear localization of p53 upon binding and phosphorylation of $\mathrm{mdm} 2$ [120]. Therefore, deregulation of the PI3K-Akt pathway can be considered as a cause of chemoresistance [127].

\subsection{Immunogenecity of cancer cell death}

It is becoming more evident that the immune response facilitates the effects of chemotherapy. Physiological death avoids autoimmunity. However cancer cell death triggered by radiotherapy or some chemotherapeutic agents such as anthracyclines can be immunogenic [128]. Immunogenic death involves changes in the composition of the cell membrane and the release of molecules called Damage Associated Molecular Patterns or alarmins. In particular, calreticulin has been shown to be crucial for immunogenic cancer cell death [129]. The immune system determines the long-term success of antitumor therapies. It seems that mitochondrial events as well as the ER response in conjunction with autophagy can establish whether cancer cells die in response to chemotherapy [130]. It has been found that calreticulin is the dominant pro-phagocytic signal on several cancers including neuroblastoma, non Hodgkin's lymphoma and bladder cancer. However, calreticulin is counterbalanced by the "don't eat me" signal CD47, which prevents cancer cell phagocytosis and is also highly expressed in these tumours [131]. Moreover, since CD47 is expressed on the surface of all human cancer cells but not in normal cells, blocking CD47 function with antibodies is emerging as a novel potential cancer strategy [132].

\section{Senescence and cancer}

We have already mentioned that strong p53 activation induces apoptosis. However, Leontieva and colleagues have shown that a weak and sustained p53 activation during cell cycle arrest can promote a different type of cell demise known as senescence [133]. Cellular senescence, induced after an irreversible cell cycle arrest, is a protective mechanism that limits proliferation of cells exposed to endogenous or exogenous insults. This cell death type can take part in processes of tumour suppression, tumour promotion, aging, and tissue repair [134]. Senescent cells become flattened and enriched with vacuoles. Some of the biochemical changes characteristic of senescence include elevation in $\beta$-galactosidase activity at an acidic $\mathrm{pH}$, increase in senescence markers (p16, p15, p21, p53, ARF, etc.), heterochromatinization and, similarly to autophagy, formation of autolysosomes. It has been recently shown that chemotherapeutic agents may cause a form of "premature senescence" that can be considered as a tumour suppressor mechanism. Therefore, the induction of premature senescence as a drug-inducible arrest program has therapeutic potential for cancer treatment, but requires further investigation [135].

\section{Autophagy and cancer}

Regarding the role played by autophagy in cancer, mounting evidences suggest that autophagic cell death functions as a tumour suppressor mechanism. Several tumour 
suppressor proteins have been shown to induce autophagy. Supporting this idea, there are also several works showing that certain oncogenic proteins inhibit autophagy. Most of this oncogene products form part of the classic PI3K-Akt-mTOR pathway. In the following section, we summarize the literature on the role played by key tumour suppressors and oncogene products in the regulation of autophagy and the involvement of autophagic genes in cancer.

\subsection{Tumour suppressor genes that regulate autophagy}

To date, several tumour suppressor proteins that regulate autophagy have been described. These include: Beclin 1, UV irradiation-resistance-associated gene (UVRAG), PTEN, Bcl-2, and p53. The majority of them act as autophagy inducers with the exception of p53 that is able to activate or inhibit autophagy.

Role of Beclin 1 in autophagy: Beclin1 is a key regulator of autophagy. It regulates the autophagic process at different levels by combining with the enzyme class III PI3K (PI3KC3) and specific group of proteins forming unique class III PI3K-Beclin complexes. This PI3KC3Beclin complex functions as a core complex during autophagy $[136,137]$ by phosphorylating phosphatidylinositol to produce phosphatidylinositol 3-monophosphate, which presumably allows the recruitment of essential autophagy related (Atg) proteins to the membrane. In mammals, at least three types of class III PI3-kinase-Beclin complexes contribute to autophagy $[84,138,139]$.

Role of Beclin 1 in tumour suppression vs. autophagy: The first link between autophagy and cancer was established in 1999, when Liang and colleagues discovered that the autophagic protein Beclin 1 was able to inhibit tumourigenesis [140]. Beclin 1 is a tumour suppressor gene [141,142] monoallelically deleted in many types of cancers, including ovary $(75 \%)$, breast $(50 \%)$ and prostate $(40 \%)$. Several studies suggest that the activation of autophagy by Beclin 1 is tightly associated with its tumour suppression function. For example, overexpression of Beclin-1 in the human MCF-7 breast carcinoma cell line is associated with inhibition of cell proliferation and induces autophagy [140]. In contrast, studies in vivo demonstrate that the monoallelic disruption of Beclin 1 gene promotes cellular proliferation and reduces autophagy [142]. Furthermore, genetically engineered mouse models with heterozygous disruption of Beclin 1 have decreased autophagy and are more prone to develop tumours, including lung carcinomas, hepatocellular carcinomas, lymphomas and mammary precancerous lesions $[141,143]$. Taken together, these studies firmly support the notion that autophagy induction and tumour inhibition function of Beclin 1 are closely interconnected.

UVRAG is another tumour suppressor protein that is able to activate autophagy. UVRAG is a positive regulator of Beclin 1, as it promotes its binding to PI3KC3 to form the complex and enhance Beclin 1 activity. Through mediating Beclin 1-PI3KC3 complex, UVRAG can promote autophagy, thus inhibiting carcinogenesis of human colon cancer cells. It has also been proposed that UVRAG is involved in causing membrane curving [144]. Furthermore, 
the monoallelic deletion or mutation of UVRAG has been observed in several human cancers such as colon, gastric and breast cancer [145-147].

Bif- 1 is also a tumour suppressor that promotes autophagy. Similar to UVRAG, Bif-1 is a positive regulator of Beclin 1, as it enhances its interaction with PI3KC3, thus increasing autophagy. Consistently, it has been shown that loss of Bif- 1 prevented the formation of autophagosomes and induced the development of spontaneous tumours in mice [144]. Furthermore, expression of Bif-1 is significantly reduced in prostate, colon, urinary bladder and gastric tumours [146,148,149]. The precise mechanism of Bif-1 in suppressing tumourigenesis has not been fully clarified, but it is reasonable to presume that its tumour inhibitory activity is associated with its role in inducing autophagy. Some groups have also suggested that Bif-1 suppresses tumour growth through its interaction with proapoptotic Bax [150].

\subsection{Oncogenic genes that regulate autophagy}

Most of the oncogenic genes that regulate autophagy described to date are key proteins of the PI3K-Akt-mTOR pathway. These proteins inhibit autophagy and promote carcinogenesis.

mTOR: the best-studied downstream substrate of Akt is the serine/threonine kinase mammalian target of rapamycin (mTOR). In mammals, mTOR exists in two different complexes, known as mTORC1 and mTORC2. In the mTORC1 complex, mTOR is bound to a protein called Raptor, and in the mTORC2 complex, mTOR is bound to Rictor. mTORC1 is best known for its role in regulating protein synthesis through two of its substrates, 4E-BP1 and p70S6K [151]. Akt can directly phosphorylate and activate mTOR, or activate it indirectly by phosphorylation and inactivation of TSC2. When TSC2 is inactivated by phosphorylation, it can no longer associate with TSC1, thus abolishing the inhibitory effect of TSC1-TSC2 complex on mTORC1. As a result, mTOR is activated and signals to its downstream targets p70S6 kinase, ribosomal protein S6 and 4EBP-1/eIF-4E to control protein translation and proliferation [152]. mTORC1 is not only a key regulator of proliferation and survival, but also a master inhibitor of autophagy. Under nutrient-rich conditions, mTORC1 is activated and phosphorylates ULK1, ULK2 and mAtg13, inhibiting the initiation of autophagy. In contrast, in nutrient starvation conditions mTORC1 is inactivated and dissociates, resulting in activation of ULK1 and ULK2, which initiates the autophagy cascade [151]. The PI3K-Akt-mTOR pathway is probably the most commonly activated signalling pathway in human cancers [124]. This route is activated aberrantly in many types of tumours, and hence, inhibited autophagy and increased proliferation and protein synthesis are often observed. For example, many human cancers are characterized by activating mutations in specific components of the signalling pathway that connect Receptor tyrosine kinases to mTOR, including Ras, PI3K and Akt. Somatic mutations in PIK3CA gene encoding the catalytic subunit of class I PI3K frequently occur in cancers of colon, breast, brain and lung [153]. PTEN, another regulator of PI3KI-Akt pathway, is a tumour suppressor that is found to be mutated in many types of cancer. 
Bcl-2 forms part of the Bcl-2 family proteins. For almost two decades, Bcl-2 has been regarded to function as an antiapoptotic protein that contributes to tumourigenesis. The role of Bcl-2 in autophagy was realized in 1998 when Liang identified Beclin 1 as Bcl-2 interacting protein [140]. Bcl-2 acts as a negative regulator of autophagy by inhibiting Beclin 1. It binds constitutively to Beclin 1, blocking the interaction between Beclin 1 and PI3KC3 [154-156]. As a result, PI3KC3 activity is decreased and autophagy is downregulated [155]. The binding of Bcl-2 with Beclin 1 seems to be constitutive, and its detachment from Beclin 1 is speculated to be essential in autophagy.

\subsection{How does autophagy suppress tumourigenesis?}

The combined data presented above strongly support the idea that autophagy functions as a tumour suppressor process. Consistent with this, oncogenes that have a role in autophagy are potent inhibitors of this process. Although the molecular mechanisms by which autophagy functions in tumour suppression are poorly defined, at least two mechanisms have been described:

a. Autophagy maintains the integrity of the genome

The first hypothesis is that autophagy may function as a housekeeping pathway to exert the quality control of organelles, proteins and DNA. Mathews and colleague observed that in autophagy deficient tumour cells, metabolic stress promotes the accumulation of p62, damaged mitochondria and ROS generation, promoting genomic instability and leading to oncogene activation and tumour progression [157,158]. Furthermore, immortalized mouse epithelial cells with a defect in ATG genes (loss of Beclin 1 or Atg 5) display increased DNA damage, centrosome abnormalities, numerical and structural chromosomal abnormalities and gene amplification, especially after ischemic stress.

However, the mechanisms through which autophagy preserves the integrity of the genome remains elusive. One possibility could be that autophagy may contribute to cell cycle regulation, for example by degrading organelles and/or proteins involved in the cell cycle checkpoints [159]. Another possibility is that autophagy might simply function at a more general level to ensure the minimal amount of ATP and other metabolites required for DNA repair. Finally, autophagy may act by removing old and/or damaged organelles (for example, uncoupled mitochondria) which may act as a source of genotoxic chemical species such as ROS.

\section{b. Autophagy limits necrosis-mediated inflammation}

Necrosis normally results from physical injury in which the cell lyses and releases its intracellular contents, which activate the innate immune system and a wound-healing response [160]. As a result, inflammatory cells are recruited and cytokines are released to promote cell growth to replace the damaged tissue [161,162].

In contrast, apoptosis may be the preferred means of cell demise for cells upon metabolic stress, as cells are eliminated without inflammation. However, in cancer cells with a defect 
in apoptosis, autophagy is induced for cell survival. Through autophagy, cells eliminate damaged organelles and may maintain their normal cellular function under adverse conditions of fluctuating oxygen and nutrient supply. However, this beneficial effect of autophagy functions during short term interruptions in nutrient availability, as in the long term (excess of autophagy) it can possibly lead to cell death.

A high proportion of tumours have been seen to present a defect both in autophagy and apoptosis. Degenhardt and colleagues have shown that the inhibition of both processes under conditions of metabolic stress generates a necrotic cell-death, suggesting that apoptosis and autophagy function to limit necrosis [163]. In these necrotic tumours a persistent inflammatory infiltration and cytokine production exists, which is thought to promote tumour growth and thus, is associated with poor prognosis.

\subsection{Role of autophagy in tumour survival}

The data presented above strongly supports the idea that autophagy functions as a tumour suppressor process and that inhibition of autophagy leads to carcinogenesis. However, there are some circumstances where autophagy contributes to tumour survival promoting carcinogenesis:

a. Autophagy is induced by nutrient starvation

The survival role of autophagy during nutrient limitation is well established. When cells encounter environmental stresses such as nutrient starvation, autophagy can be activated and protects cells by preventing them from undergoing apoptosis. Through autophagy, starving cells degrade cytoplasmic material to generate both nutrients and energy [85]. Consistent with this, during nutrient starvation, inhibition of autophagy promotes apoptosis [164].

b. Autophagy is induced by hypoxia

Hypoxia in tumours results from inadequate tumour vasculature and is associated with a more malignant phenotype, higher predisposition for metastasis, and poor prognosis. Hypoxic stress selects for cells that are resistant to apoptosis as well as poses a major barrier to chemotherapy and radiotherapy.

White and colleagues first showed that autophagy is induced specifically in the hypoxic core of tumours, where it promotes survival [163]. Further studies have unveiled the molecular connections between hypoxia and the activation of autophagy. For example, it has been reported that when oxygen concentration falls below $5 \%$ hypoxia inducible factor 1 (HIF1) is activated and this transcription factor activates key autophagy inducers (BNIP3), which in turn activate the key autophagy complex formed by PI3K III $[165,166]$. Further mechanistic studies have revealed that induction of BNIP3 and BNIP3L in hypoxic cells disrupts the Becn1-Bcl-2 complex, thereby releasing Becn1 to induce autophagy [167]. 
The role of autophagy as a key mediator of survival of hypoxic cells is emerging so that the exact mechanisms underlying this phenotype remain unclear. Because chronic hypoxia leads to major metabolic perturbations in tumour tissues, one can postulate that by recycling basic cellular components, autophagy helps stressed cells cope with the increased metabolic demand [168]. However, further studies are needed to validate this hypothesis.

c. Autophagy is induced in metastatic cells

Epithelial cells critically depend on cell adhesion to extracellular matrix (ECM) for proper growth and survival. Upon detachment of cells from the ECM, cells undergo anoikis, a type of apoptotic cell death that serves the homeostatic function of killing cells that have lost contact with the basement membrane [68]. It has been shown that autophagy is induced in oncogene-transformed cells following matrix detachment [169]. Similarly, in three dimensional (3D) epithelial cell culture models, autophagy is significantly increased in the detached luminal cells. Furthermore, when autophagy is inhibited accelerated luminal clearance occurs $[158,169]$. Altogether, these results suggest that autophagy is fundamental in anoikis resistance, a process exploited by tumour cells to survive after detachment from the primary site, as well as while migrating to distant metastatic sites [170].

Debnath and colleagues have shown that detachment induces autophagy in both nontumourigenic epithelial cell lines and in primary epithelial cells. Autophagy inhibition through siRNA for ATG genes inhibits detachment-induced autophagy and increases apoptosis. Remarkably, even when apoptosis is inhibited matrix-detached cells still exhibit autophagy. Moreover, inhibition of autophagy in MCF-10 acini enhances luminal apoptosis during morphogenesis and fails to elicit long-term luminal filling [171]. Altogether, these results indicate that autophagy promotes epithelial cell survival during anoikis, including in detached cells harbouring antiapoptotic lesions.

\section{Current therapeutic advances}

In addition to inactivation of proliferative and prosurvival oncogenic pathways, current anticancer strategies deal with reactivation of cancer death cell signalling routes in order to induce tumour regression. The most promising cancer therapies that specifically target apoptosis, necrosis/necroptosis and autophagy are described in the following section.

\subsection{Extrinsic apoptotic pathway}

TRAIL: This member of the TNF family stimulates the extrinsic apoptotic pathway in a wide variety of cancers upon binding to death receptors, while having no effect on normal cells. Therefore, the use of recombinant TRAIL or agonistic TRAIL-receptor antibodies constitutes a novel therapeutic strategy [172]. TRAIL has been found to bind five receptors in human cells: TRAIL-R1, TRAIL-R2, TRAIL-R3 (DcR1), TRAIL-R4 (DcR2) and the soluble receptor osteoprogeterin. However, DcR1 and DcR2 are unable to transduce a death signal and are considered "decoy receptors". Ashkenazi and colleagues have proposed that the specificity 
of TRAIL for cancer cells is due to the fact that normal cells express more frequently these decoy receptors [173]. Moreover, TRAIL only weakly induces the prosurvival NFkB pathway [78]. Unfortunately, many primary tumour cell lines have shown resistance to TRAIL [174]. It has been shown that in preclinical studies, the combination of recombinant human TRAIL (rhTRAIL, AMG951, Dulanermin) or agonistic antibodies with irradiation, several chemotherapeutic agents, Akt or proteosome inhibitors induced cell death in tumours resistant to TRAIL [175-177]. Therefore, the efficacy of rhTRAIL or anti-TRAIL-R1/2 antibodies is being examined in different phase I and phase II clinical trails alone or in combination with other chemotherapeutic agents [172,178,179].

Fas activating compounds: Fas, also called CD95 or APO-1 is a member of the TNF family of death receptors involved in the extrinsic apoptotic pathway. Fas plays an important role in regulation of the immune system. This receptor belongs to a subgroup within the TNFR family which includes TNFR1, DR3, TRAIL-R4 and TRAIL-R5 [180]. Fas has been recently implicated in the activation of RIP1, resulting in necroptosis when caspase- 8 is inactive [181,182]. In addition, Tschopp and colleagues have demonstrated that Fas can activate other signalling pathways involved in proliferation or differentiation [109]. Fas agonists, such as highly aggregated FasL or anti-Fas antibodies are not suitable for cancer therapy owing to their profound liver toxicity. However, weaker Fas agonists may be useful. In this respect, APO010 is undergoing clinical trials for solid tumours [109].

\subsection{Intrinsic apoptotic pathway}

Bcl-s inhibitors/BH3 mimetics: Many efforts in cancer therapeutics are directed towards inhibition of antiapoptotic Bcl-2 like proteins. The first class of drugs being developed was antisense nucleotides. Oblimersen has been tested in clinical trials in different types of cancers. Even though some clinical trials shows efficacy of oblimersen combined with chemotherapy in treating melanoma [183], other studies show that this Bcl-2 inhibitor does not confer significant benefit to cancer patients [178]. Small molecule Bcl-2 inhibitors are also called "BH3 mimetics", as they imitate the function of BH3-only proteins: Gossypol (AT101) binds Bcl-2, Bcl- $\mathrm{X}_{\mathrm{L}}$ and $\mathrm{MCl}-1$, inhibiting their binding to Bax and Bak. In combination with other chemotherapeutic agents it promotes apoptosis in preclinical studies and has shown efficacy in at least one clinical trial [178]. Obotoclax is a pan Bcl-2 inhibitor that induces apoptosis in leukemia cells. However, recent studies have shown that its activity is partially mediated by autophagy $[184,185]$. Therefore, caution should be taken when using these kinds of drugs. ABT-737 and its orally available derivative, ABT-263 (navitoclax), have shown promising results in preclinical studies. They bind Bcl-2, Bcl- $\mathrm{X}_{\mathrm{L}}$ and Bcl-w [186], but mildly inhibit Mcl-1 [187] or A1 [101]. ABT-727 synergizes with standard chemotherapeutic agents, radiation and tyrosine kinase inhibitors in cancer cells and is effective as a single agent promoting tumour regression in mice. ABT-263 is currently in phase I and II clinical trails as a single agent [78,188]. However, its use is limited because it causes trombocytophenia owing to Bcl- $\mathrm{X}_{\mathrm{L}}$ inhibition [189]. A new BH-3 mimetic agent, GDC-0199 has been developed and entered clinical trails for lymphomas [101]. 
IAP inhibitors and Smac mimetics: Moreover, the role of IAPs in regulating apoptosis and/or necroptosis has led to the development of small molecules that antagonize IAP, or mimic the function of Smac/DIABLO. In fact, IAPs have been found to be overexpressed in many cancers and to be associated with poor prognosis and chemoresistance [102], making them putative targets for cancer therapeutics. Smac mimetics can sensitize chemoresistant cancer cells to cisplatin, doxorubicin or TRAIL [190], either as single agents or in combination with other drugs [109]. Therefore, some of these agents (AT-406, LCL-161, HGS-1029, TL32711, GDC-0917) [73] have recently entered clinical trials [191] for the treatment of solid tumours and lymphomas [192]. However, the potential of Smac mimetics as antitumour agents has been questioned, since the inhibition of cIAP1 and cIAP2 can stabilize IKK and activate the proinflammatory NFkB pathway [102].

Other IAP-targeted therapies such as XIAP and survivin antisense oligonucleotides have been developed [102]. Antisense oligonucleotides against survivin synergize with etoposide in non small lung cancer cells [117]. LY2181308 is a second generation antisense oligonucleotide being evaluated in clinical trials. In addition, a small molecule inhibitor of survivin, YM155, has shown potency in preclinical models and has entered phase II clinical trails [110].

\subsection{DNA damage and cell cycle}

p53 inhibitors: Since p53 is frequently mutated in tumours, therapeutic approaches have been made to restore p53 function. Since p53 is targeted to degradation through interaction with mdm2, some drugs such as RITA, Nutlin-3 or HLI198 have been designed to disrupt p53$\mathrm{mdm} 2$ interaction. These compounds bind to the $\mathrm{p} 53$ binding site on $\mathrm{mdm} 2$ or inhibit $\mathrm{mdm} 2$ ubiquitin ligase activity. This approach is valid in cancers with wild type p53, such as haematological malignancies [56]. A second approach is to rescue wild-type 53 function in p53-mutated tumours. PRIMA-1 restores sequence-specific DNA binding and active conformation of mutant p53 proteins. PRIMA-1 can synergize with conventional chemotherapeutic drugs and inhibit tumour growth in mice with no apparent toxicity and has recently entered clinical trials [78].

Chk1/2 inhibitors: The concept of "synthetic lethality" coined by Kaelin, by which two molecular lesions combine to have a lethal effect on the cell, although neither of them is harmful individually, has recently gained interest [193,194]. In this context, Chk inhibitors may have a therapeutic potential in p53-mutated tumours. UCN-01, the first Chk inhibitor evaluated in humans, has limited clinical value due to its toxicity. Other Chk inhibitors functioning as checkpoint abrogators that are being evaluated in clinical trials are: AZD7762, LY26303618, CBT501, PF-00477736, SCH 900776, XL844, and the wee-1 inhibitor MK-1775 [195,196].

PARP inhibitors: Other example of synthetic lethality is BRCA mutant breast cancer. BRCA1 and BRCA2 play a role in homologous recombination, an important repair pathway for 
DNA double strand breaks. The current hypothesis is that since PARP is involved in repairs in DNA single strands breaks, inhibition of PARP leads to accumulation of single strand unrepaired breaks and becomes synthetically lethal in BRCA-mutated cancers [197]. Several PARP inhibitors are being evaluated in clinical trials: AG014699, AZD2281 (olaparib), ABT888 (veliparib), BSI-201 (iniparib), INO-1001, GP121016, CEP-9722 and MKI4827 $[197,198]$. PARP inhibitors may be useful in tumours bearing other types of genomic or functional defects in DNA damage response pathways.

\subsection{Necroptosis}

cFLIP: This antiapoptotic regulator is expressed as long (c-FLIPL) short (c-FLIPS) or c-FLIPR variants in human cells. In the absence of cFLIP, the ripoptosome triggers apoptotic cell death. On the contrary, expression of CFLIPL, which binds caspase- 8 , neutralizes its ability to engage the apoptotic machinery, but inhibits necroptosis by preventing RIP1-RIP3 association. On the other hand, c-FLIPs, although is able to bind caspase- 8 , does not form an active heteromer and necroptosis can develop [78,199]. Increased expression of c-FLIP has been found in several human cancers and is associated with poor prognosis [102]. Downregulation of FLIP seems to be a promising therapeutic strategy. Research efforts are being focused on the development of small interference RNA (siRNA) targeted against cFLIP. In addition, several antitumour agents can downregulate c-FLIP at the transcriptional or posttranscriptional level [200].

\subsection{Autophagy}

a. Autophagy as a protective mechanism

A large series of anticancer drugs (both clinically approved and experimental) are able to induce a significant accumulation of autophagosomes in tumour cells both in vitro and in vivo [201]. For many years, it was thought that these therapies may kill tumours through autophagy and this massive vacuolization of the cytoplasm has been considered a manifestation of autophagic cell death. According to this notion, autophagy would represent another mechanism of cell death and the inhibition of autophagy would protect the cell from dying. However, this perspective is nowadays rather discredited, as the majority of the literature has reported that specific inhibition of autophagy (through siRNA) contributes to cell death during cancer treatment [202-204]. Besides, it is now well accepted that acquired resistant to chemotherapeutic drugs is, in part, due to the adaptive prosurvival response conferred by autophagy. Also, several studies have shown that inhibition of autophagy by pharmacological inhibitors such as Bafilomycin A1, cloroquine, or 3methyladenine can enhance and accelerate cytotoxic cancer therapy in several tumours [205207]. In particular, some reports show that chloroquine as a single agent is sufficient to promote tumour regression in transplanted cancer models [208,209]. Moreover, chloroquine is a well-tolerated nontoxic drug that has entered a clinical trail as monotherapy for pancreatic cancer treatment [78]. This clearly indicates that the induction of autophagy represents an 
attempt of the cells to cope with the stress induced by cytotoxic drugs and suggests that the inhibition of the autophagic process might be beneficial in cancer treatment.

b. Autophagy as a death mechanism

Although there is robust evidence indicating that autophagy has a protective role in cancer therapeutics, in certain cancer treatments, autophagy can kill cells by inducing autophagic cell death. For example, Abe and colleagues have demonstrated that harmol, a $\beta$-carboline alkaloid, triggered autophagic cell death in human lung carcinoma A549 cells without activation of caspase-3, caspase-8, or caspase- 9 or PARP cleavage. Autophagy, but not apoptosis, was detected by electron microscopy in these cancer cells. Furthermore, pretreatment of A549 cells with the autophagy inhibitor 3-methyladenine or siRNAmediated knockdown of LC3 suppressed harmol-induced cell death [210]. Another study shows that L929 fibrosarcoma cells die in a caspase-independent manner involving autophagy and that ATG genes are required for this cell death process [211]. In this model, caspase inhibition induces the selective autophagic degradation of catalase, a major ROS scavenger, and the resulting ROS accumulation promotes autophagic cell death [212].

\subsection{What determines if autophagy is cytoprotective or cytotoxic?}

Autophagy is a process that allows cells to escape death or paradoxically leads to cell death. It is not yet understood what factors determine whether autophagy is cytoprotective or cytotoxic. It has been suggested that autophagy induced under pathological conditions functions as an adaptive cell response, allowing the cell to survive bioenergetic stress. However, autophagy is a process that destroys cellular content and organelles. In this way, it has been suggested that deregulated, excessive or persistent autophagy may lead to autophagic cell death. That is, the destruction of proteins and organelles may pass a threshold, leading to cell death. However, the point at which autophagy becomes autophagic cell death remains unclear. In this perspective, the dissection of the transition from autophagy to autophagic cell death and the cross-talking between apoptosis and autophagy may help to understand this process, leading to more efficacious treatments in cancer. In contrast, a different study has reported that when cells are subjected to prolonged growth factor deprivation or shortage of glucose and oxygen they can lose the majority of their mass via autophagy. However, when these cells are placed in optimal culture conditions, they are able to fully recover $[163,213]$. This result suggests that cell death via autophagy may not be simply a matter of crossing a quantitative threshold of self-digestion.

\subsection{Interplay among apoptosis, necrosis/necroptosis and autophagy}

Cell death process in vivo involves a complex interaction among apoptosis, necrosis/necroptosis and autophagy [78]. In some situations, a specific stimulus triggers only one mechanism, but in other cases, the same stimulus can evoke more than one cell demise machinery. Therefore, several mechanisms can coexist within a cell, but only one will predominate over the others. The decision to undergo apoptosis, necrosis/necroptosis or 
autophagy depends on various factors: energy/ATP availability, extent of the stress and the damage and presence of inhibitors of particular pathways (e. g. caspases inhibitors) [214]. ATP depletion activates autophagy, but if autophagy fails to maintain energy levels, necrosis/necroptosis results [215]. Apoptosis is usually triggered with sufficient ATP levels to trigger caspases. If the damage is severe necrosis prevails over apoptosis [216,217]. Hence, apoptosis is the first choice in most circumstances and necroptosis is triggered only as a backup alternative to guarantee that cell death takes place. However, in some cases (e.g. viral infection) TNF-mediated necroptosis predominate [218]. Apoptosis can inhibit autophagy through Bcl-2-mediated sequestration [155,156] or caspase-dependent cleavage of Beclin 1 [219,220,220], and conversely, autophagy can inhibit apoptosis by caspase- 8 degradation [221].

\section{Concluding remarks}

Programmed cell death mechanisms are intricate and usually interconnected processes. Evasion of cell death is a common feature of cancer cells leading to chemoresistance. Apoptosis, necrosis/necroptosis and autophagy are the main explored pathways that had gained interest among cancer biologists, as means to develop novel cancer therapeutics. Deeping our knowledge on the nexus between cell death and cancer will enable us to predict in a more refined manner the carcinogenic process and therefore, pave the way for a personalized approach to the disease.

\section{Author details}

Silvina Grasso, Estefanía Carrasco-García, Lourdes Rocamora-Reverte, Ángeles Gómez-Martínez and José A. Ferragut

Instituto de Biología Molecular y Celular, Universidad Miguel Hernández, Elche (Alicante), Spain

M. Piedad Menéndez-Gutiérrez

Instituto de Biología Molecular y Celular, Universidad Miguel Hernández, Elche (Alicante), Spain

Centro Nacional de Investigaciones Cardiovasculares, Departamento de Desarrollo y Reparación

Cardiovascular, Madrid, Spain

Leticia Mayor-López, Elena Tristante, Isabel Martínez-Lacaci*

Instituto de Biología Molecular y Celular, Universidad Miguel Hernández, Elche (Alicante), Spain

Unidad AECC de Investigación Traslacional en Cáncer, Hospital Universitario Virgen de la Arrixaca, Instituto Murciano de Investigación Biosanitaria, Murcia, Spain

Pilar García-Morales and Miguel Saceda

Instituto de Biología Molecular y Celular, Universidad Miguel Hernández, Elche (Alicante), Spain

Unidad de Investigación, Hospital General Universitario de Elche, Elche (Alicante), Spain

${ }^{*}$ Corresponding Author 


\section{References}

[1] Vaux DL, Korsmeyer SJ (1999) Cell death in development. Cell ;96: 245-254.

[2] Vermeulen K, Van Bockstaele DR, Berneman ZN (2005) Apoptosis: mechanisms and relevance in cancer. Ann.Hematol.84: 627-639.

[3] deCathelineau AM, Henson PM (2003) The final step in programmed cell death: phagocytes carry apoptotic cells to the grave. Essays Biochem.39: 105-117.

[4] Kerr JF, Wyllie AH, Currie AR (1972) Apoptosis: a basic biological phenomenon with wide-ranging implications in tissue kinetics. Br.J.Cancer ;26: 239-257.

[5] Kroemer G, Galluzzi L, Vandenabeele P, Abrams J, Alnemri ES, Baehrecke EH, et al. (2009) Classification of cell death: recommendations of the Nomenclature Committee on Cell Death 2009. Cell Death.Differ.16: 3-11.

[6] Wyllie AH, Kerr JF, Currie AR (1980) Cell death: the significance of apoptosis. Int.Rev.Cytol.68: 251-306.

[7] Zamzami N, Marchetti P, Castedo M, Zanin C, Vayssiere JL, Petit PX, et al. (1995) Reduction in mitochondrial potential constitutes an early irreversible step of programmed lymphocyte death in vivo. J.Exp.Med.181: 1661-1672.

[8] Martin SJ, Reutelingsperger CP, McGahon AJ, Rader JA, van Schie RC, LaFace DM, et al. (1995) Early redistribution of plasma membrane phosphatidylserine is a general feature of apoptosis regardless of the initiating stimulus: inhibition by overexpression of Bcl-2 and Abl. J.Exp.Med.182: 1545-1556.

[9] Majno G, Joris I (1995) Apoptosis, oncosis, and necrosis. An overview of cell death. Am.J.Pathol.146: 3-15.

[10] Hail N, Jr., Carter BZ, Konopleva M, Andreeff M (2006) Apoptosis effector mechanisms: a requiem performed in different keys. Apoptosis.11: 889-904.

[11] Galluzzi L, Vitale I, Abrams JM, Alnemri ES, Baehrecke EH, Blagosklonny MV, et al. (2012) Molecular definitions of cell death subroutines: recommendations of the Nomenclature Committee on Cell Death 2012. Cell Death.Differ.19: 107-120.

[12] Kroemer G, Galluzzi L, Brenner C (2007) Mitochondrial membrane permeabilization in cell death. Physiol Rev.87: 99-163.

[13] Ellis HM, Horvitz HR (1986) Genetic control of programmed cell death in the nematode C. elegans. Cell ;44: 817-829.

[14] Thornberry NA, Lazebnik Y (1998) Caspases: enemies within. Science ;281: 1312-1316.

[15] Pop C, Salvesen GS (2009) Human caspases: activation, specificity, and regulation. J.Biol.Chem.284: 21777-21781.

[16] Kumar S (2007) Caspase function in programmed cell death. Cell Death.Differ.14: 32-43.

[17] Blank M, Shiloh Y (2007) Programs for cell death: apoptosis is only one way to go. Cell Cycle ;6: 686-695.

[18] Cohen GM (1997) Caspases: the executioners of apoptosis. Biochem.J.326 ( Pt 1): 1-16.

[19] Tenev T, Zachariou A, Wilson R, Ditzel M, Meier P (2005) IAPs are functionally nonequivalent and regulate effector caspases through distinct mechanisms. Nat.Cell Biol.7: 70-77. 
[20] Huang H, Joazeiro CA, Bonfoco E, Kamada S, Leverson JD, Hunter T (2000) The inhibitor of apoptosis, cIAP2, functions as a ubiquitin-protein ligase and promotes in vitro monoubiquitination of caspases 3 and 7. J.Biol.Chem.275: 26661-26664.

[21] Suzuki Y, Nakabayashi Y, Takahashi R (2001) Ubiquitin-protein ligase activity of Xlinked inhibitor of apoptosis protein promotes proteasomal degradation of caspase-3 and enhances its anti-apoptotic effect in Fas-induced cell death. Proc.Natl.Acad.Sci.U.S.A ;98: 8662-8667.

[22] Yang QH, Church-Hajduk R, Ren J, Newton ML, Du C (2003) Omi/HtrA2 catalytic cleavage of inhibitor of apoptosis (IAP) irreversibly inactivates IAPs and facilitates caspase activity in apoptosis. Genes Dev.17: 1487-1496.

[23] Danial NN, Korsmeyer SJ (2004) Cell death: critical control points. Cell ;116: 205-219.

[24] Meier P, Vousden KH (2007) Lucifer's labyrinth--ten years of path finding in cell death. Mol.Cell ;28: 746-754.

[25] Peter ME, Budd RC, Desbarats J, Hedrick SM, Hueber AO, Newell MK, et al. (2007) The CD95 receptor: apoptosis revisited. Cell ;129: 447-450.

[26] Lavrik I, Golks A, Krammer PH (2005) Death receptor signaling. J.Cell Sci.118: 265-267.

[27] Green DR, Kroemer G (2004) The pathophysiology of mitochondrial cell death. Science ;305: 626-629.

[28] Tait SW, Green DR (2010) Mitochondria and cell death: outer membrane permeabilization and beyond. Nat.Rev.Mol.Cell Biol.11: 621-632.

[29] Luo X, Budihardjo I, Zou H, Slaughter C, Wang X (1998) Bid, a Bcl2 interacting protein, mediates cytochrome $\mathrm{c}$ release from mitochondria in response to activation of cell surface death receptors. Cell ;94: 481-490.

[30] Chinnaiyan AM, Tepper CG, Seldin MF, O'Rourke K, Kischkel FC, Hellbardt S, et al. (1996) FADD/MORT1 is a common mediator of CD95 (Fas/APO-1) and tumor necrosis factor receptor-induced apoptosis. J.Biol.Chem.271: 4961-4965.

[31] Carswell EA, Old LJ, Kassel RL, Green S, Fiore N, Williamson B (1975) An endotoxininduced serum factor that causes necrosis of tumors. Proc.Natl.Acad.Sci.U.S.A ;72: 36663670.

[32] Schievella AR, Chen JH, Graham JR, Lin LL (1997) MADD, a novel death domain protein that interacts with the type 1 tumor necrosis factor receptor and activates mitogen-activated protein kinase. J.Biol.Chem.272: 12069-12075.

[33] Yang J, Liu X, Bhalla K, Kim CN, Ibrado AM, Cai J, et al. (1997) Prevention of apoptosis by Bcl-2: release of cytochrome c from mitochondria blocked. Science ;275: 1129-1132.

[34] Vandenabeele P, Galluzzi L, Vanden Berghe T, Kroemer G (2010) Molecular mechanisms of necroptosis: an ordered cellular explosion. Nat.Rev.Mol.Cell Biol.11: 700-714.

[35] Galluzzi L, Zamzami N, de La Motte RT, Lemaire C, Brenner C, Kroemer G (2007) Methods for the assessment of mitochondrial membrane permeabilization in apoptosis. Apoptosis.12: 803-813.

[36] Adams JM, Cory S (2007) The Bcl-2 apoptotic switch in cancer development and therapy. Oncogene ;26: 1324-1337. 
[37] Bidere N, Lorenzo HK, Carmona S, Laforge M, Harper F, Dumont C, et al. (2003) Cathepsin D triggers Bax activation, resulting in selective apoptosis-inducing factor (AIF) relocation in $\mathrm{T}$ lymphocytes entering the early commitment phase to apoptosis. J.Biol.Chem.278: 31401-31411.

[38] Cirman T, Oresic K, Mazovec GD, Turk V, Reed JC, Myers RM, et al. (2004) Selective disruption of lysosomes in HeLa cells triggers apoptosis mediated by cleavage of Bid by multiple papain-like lysosomal cathepsins. J.Biol.Chem.279: 3578-3587.

[39] Thomas DA, Scorrano L, Putcha GV, Korsmeyer SJ, Ley TJ (2001) Granzyme B can cause mitochondrial depolarization and cell death in the absence of BID, BAX, and BAK. Proc.Natl.Acad.Sci.U.S.A ;98: 14985-14990.

[40] Datta SR, Dudek H, Tao X, Masters S, Fu H, Gotoh Y, et al. (1997) Akt phosphorylation of BAD couples survival signals to the cell-intrinsic death machinery. Cell ;91: 231-241.

[41] Donovan M, Cotter TG (2004) Control of mitochondrial integrity by Bcl-2 family members and caspase-independent cell death. Biochim.Biophys.Acta ;1644: 133-147.

[42] Belizario JE, Alves J, Occhiucci JM, Garay-Malpartida M, Sesso A (2007) A mechanistic view of mitochondrial death decision pores. Braz.J.Med.Biol.Res.40: 1011-1024.

[43] Szabadkai G, Rizzuto R (2004) Participation of endoplasmic reticulum and mitochondrial calcium handling in apoptosis: more than just neighborhood? FEBS Lett.567: 111-115.

[44] Thomenius MJ, Wang NS, Reineks EZ, Wang Z, Distelhorst CW (2003) Bcl-2 on the endoplasmic reticulum regulates Bax activity by binding to $\mathrm{BH} 3$-only proteins. J.Biol.Chem.278: 6243-6250.

[45] Liu X, Kim CN, Yang J, Jemmerson R, Wang X (1996) Induction of apoptotic program in cell-free extracts: requirement for dATP and cytochrome c. Cell ;86: 147-157.

[46] Wang D, Liang J, Zhang Y, Gui B, Wang F, Yi X, et al. (2012) Steroid Receptor Coactivator-interacting Protein (SIP) Inhibits Caspase-independent Apoptosis by Preventing Apoptosis-inducing Factor (AIF) from Being Released from Mitochondria. J.Biol.Chem.287: 12612-12621.

[47] Norberg E, Gogvadze V, Ott M, Horn M, Uhlen P, Orrenius S, et al. (2008) An increase in intracellular $\mathrm{Ca} 2+$ is required for the activation of mitochondrial calpain to release AIF during cell death. Cell Death.Differ.15: 1857-1864.

[48] Yu SW, Wang H, Poitras MF, Coombs C, Bowers WJ, Federoff HJ, et al. (2002) Mediation of poly(ADP-ribose) polymerase-1-dependent cell death by apoptosisinducing factor. Science ;297: 259-263.

[49] Trencia A, Fiory F, Maitan MA, Vito P, Barbagallo AP, Perfetti A, et al. (2004) Omi/HtrA2 promotes cell death by binding and degrading the anti-apoptotic protein ped/pea-15. J.Biol.Chem.279: 46566-46572.

[50] Cilenti L, Soundarapandian MM, Kyriazis GA, Stratico V, Singh S, Gupta S, et al. (2004) Regulation of HAX-1 anti-apoptotic protein by Omi/HtrA2 protease during cell death. J.Biol.Chem.279: 50295-50301.

[51] Vande WL, Wirawan E, Lamkanfi M, Festjens N, Verspurten J, Saelens X, et al. (2010) The mitochondrial serine protease HtrA2/Omi cleaves RIP1 during apoptosis of Ba/F3 cells induced by growth factor withdrawal. Cell Res.20: 421-433. 
[52] Vousden KH, Lu X (2002) Live or let die: the cell's response to p53. Nat.Rev.Cancer ;2: 594-604.

[53] Berube C, Boucher LM, Ma W, Wakeham A, Salmena L, Hakem R, et al. (2005) Apoptosis caused by p53-induced protein with death domain (PIDD) depends on the death adapter protein RAIDD. Proc.Natl.Acad.Sci.U.S.A ;102: 14314-14320.

[54] Janssens S, Tinel A (2012) The PIDDosome, DNA-damage-induced apoptosis and beyond. Cell Death.Differ.19: 13-20.

[55] Bouchier-Hayes L, Lartigue L, Newmeyer DD (2005) Mitochondria: pharmacological manipulation of cell death. J.Clin.Invest ;115: 2640-2647.

[56] Yu Q (2006) Restoring p53-mediated apoptosis in cancer cells: new opportunities for cancer therapy. Drug Resist.Updat.9: 19-25.

[57] Watcharasit P, Bijur GN, Song L, Zhu J, Chen X, Jope RS (2003) Glycogen synthase kinase-3beta (GSK3beta) binds to and promotes the actions of p53. J.Biol.Chem.278: $48872-48879$.

[58] Kim I, Xu W, Reed JC (2008) Cell death and endoplasmic reticulum stress: disease relevance and therapeutic opportunities. Nat.Rev.Drug Discov.7: 1013-1030.

[59] Hoyer-Hansen M, Jaattela M (2007) Connecting endoplasmic reticulum stress to autophagy by unfolded protein response and calcium. Cell Death.Differ.14: 1576-1582.

[60] Nakagawa T, Yuan J (2000) Cross-talk between two cysteine protease families. Activation of caspase-12 by calpain in apoptosis. J.Cell Biol.150: 887-894.

[61] Morishima N, Nakanishi K, Takenouchi H, Shibata T, Yasuhiko Y (2002) An endoplasmic reticulum stress-specific caspase cascade in apoptosis. Cytochrome cindependent activation of caspase-9 by caspase-12. J.Biol.Chem.277: 34287-34294.

[62] Rao RV, Castro-Obregon S, Frankowski H, Schuler M, Stoka V, del RG, et al. (2002) Coupling endoplasmic reticulum stress to the cell death program. An Apaf-1independent intrinsic pathway. J.Biol.Chem.277: 21836-21842.

[63] Jimbo A, Fujita E, Kouroku Y, Ohnishi J, Inohara N, Kuida K, et al. (2003) ER stress induces caspase- 8 activation, stimulating cytochrome $\mathrm{c}$ release and caspase- 9 activation. Exp.Cell Res.283: 156-166.

[64] Fehrenbacher N, Jaattela M (2005) Lysosomes as targets for cancer therapy. Cancer Res.65: 2993-2995.

[65] Deacon EM, Pongracz J, Griffiths G, Lord JM (1997) Isoenzymes of protein kinase C: differential involvement in apoptosis and pathogenesis. Mol.Pathol.50: 124-131.

[66] Kharbanda S, Saxena S, Yoshida K, Pandey P, Kaneki M, Wang Q, et al. (2000) Translocation of SAPK/JNK to mitochondria and interaction with $\mathrm{Bcl}-\mathrm{x}(\mathrm{L})$ in response to DNA damage. J.Biol.Chem.275: 322-327.

[67] Ozes ON, Mayo LD, Gustin JA, Pfeffer SR, Pfeffer LM, Donner DB (1999) NF-kappaB activation by tumour necrosis factor requires the Akt serine-threonine kinase. Nature ;401: 82-85.

[68] Frisch SM, Francis H (1994) Disruption of epithelial cell-matrix interactions induces apoptosis. J.Cell Biol.124: 619-626.

[69] Gourlay CW, Ayscough KR (2005) The actin cytoskeleton: a key regulator of apoptosis and ageing? Nat.Rev.Mol.Cell Biol.6: 583-589. 
[70] Day CL, Puthalakath H, Skea G, Strasser A, Barsukov I, Lian LY, et al. (2004) Localization of dynein light chains 1 and 2 and their pro-apoptotic ligands. Biochem.J.377: 597-605.

[71] Kusano H, Shimizu S, Koya RC, Fujita H, Kamada S, Kuzumaki N, et al. (2000) Human gelsolin prevents apoptosis by inhibiting apoptotic mitochondrial changes via closing VDAC. Oncogene ;19: 4807-4814.

[72] Tang HL, Le AH, Lung HL (2006) The increase in mitochondrial association with actin precedes Bax translocation in apoptosis. Biochem.J.396: 1-5.

[73] Kaufmann SH, Desnoyers S, Ottaviano Y, Davidson NE, Poirier GG (1993) Specific proteolytic cleavage of poly(ADP-ribose) polymerase: an early marker of chemotherapy-induced apoptosis. Cancer Res.53: 3976-3985.

[74] Oliver FJ, Menissier-de MJ, de MG (1999) Poly(ADP-ribose) polymerase in the cellular response to DNA damage, apoptosis, and disease. Am.J.Hum.Genet.64: 1282-1288.

[75] Guillouf C, Wang TS, Liu J, Walsh CE, Poirier GG, Moustacchi E, et al. (1999) Fanconi anemia $C$ protein acts at a switch between apoptosis and necrosis in mitomycin Cinduced cell death. Exp.Cell Res.246: 384-394.

[76] Munoz-Gamez JA, Rodriguez-Vargas JM, Quiles-Perez R, Aguilar-Quesada R, MartinOliva D, de MG, et al. (2009) PARP-1 is involved in autophagy induced by DNA damage. Autophagy.5: 61-74.

[77] Wang Y, Dawson VL, Dawson TM (2009) Poly(ADP-ribose) signals to mitochondrial AIF: a key event in parthanatos. Exp.Neurol.218: 193-202.

[78] Long JS, Ryan KM (2012) New frontiers in promoting tumour cell death: targeting apoptosis, necroptosis and autophagy. Oncogene .

[79] Klionsky DJ (2007) Autophagy: from phenomenology to molecular understanding in less than a decade. Nat.Rev.Mol.Cell Biol.8: 931-937.

[80] Nakatogawa H, Suzuki K, Kamada Y, Ohsumi Y (2009) Dynamics and diversity in autophagy mechanisms: lessons from yeast. Nat.Rev.Mol.Cell Biol.10: 458-467.

[81] Tanida I, Ueno T, Kominami E (2004) LC3 conjugation system in mammalian autophagy. Int.J.Biochem.Cell Biol.36: 2503-2518.

[82] Mijaljica D, Prescott M, Devenish RJ (2011) Microautophagy in mammalian cells: revisiting a 40-year-old conundrum. Autophagy.7: 673-682.

[83] Majeski AE, Dice JF (2004) Mechanisms of chaperone-mediated autophagy. Int.J.Biochem.Cell Biol.36: 2435-2444.

[84] Tanida I (2011) Autophagosome formation and molecular mechanism of autophagy. Antioxid.Redox.Signal.14: 2201-2214.

[85] Yen WL, Klionsky DJ (2008) How to live long and prosper: autophagy, mitochondria, and aging. Physiology.(Bethesda.) ;23: 248-262.

[86] Castedo M, Perfettini JL, Roumier T, Andreau K, Medema R, Kroemer G (2004) Cell death by mitotic catastrophe: a molecular definition. Oncogene ;23: 2825-2837.

[87] Niikura Y, Dixit A, Scott R, Perkins G, Kitagawa K (2007) BUB1 mediation of caspaseindependent mitotic death determines cell fate. J.Cell Biol.178: 283-296.

[88] Vitale I, Galluzzi L, Castedo M, Kroemer G (2011) Mitotic catastrophe: a mechanism for avoiding genomic instability. Nat.Rev.Mol.Cell Biol.12: 385-392. 
[89] Vanlangenakker N, Vanden Berghe T, Vandenabeele P (2012) Many stimuli pull the necrotic trigger, an overview. Cell Death.Differ.19: 75-86.

[90] Feoktistova M, Geserick P, Kellert B, Dimitrova DP, Langlais C, Hupe M, et al. (2011) cIAPs block Ripoptosome formation, a RIP1/caspase-8 containing intracellular cell death complex differentially regulated by cFLIP isoforms. Mol.Cell ;43: 449-463.

[91] Tenev T, Bianchi K, Darding M, Broemer M, Langlais C, Wallberg F, et al. (2011) The Ripoptosome, a signaling platform that assembles in response to genotoxic stress and loss of IAPs. Mol.Cell ;43: 432-448.

[92] Cho YS, Challa S, Moquin D, Genga R, Ray TD, Guildford M, et al. (2009) Phosphorylation-driven assembly of the RIP1-RIP3 complex regulates programmed necrosis and virus-induced inflammation. Cell ;137: 1112-1123.

[93] Dunai Z, Bauer PI, Mihalik R (2011) Necroptosis: biochemical, physiological and pathological aspects. Pathol.Oncol.Res.17: 791-800.

[94] Martinez-Lacaci I, Garcia MP, Soto JL, Saceda M (2007) Tumour cells resistance in cancer therapy. Clin.Transl.Oncol.9: 13-20.

[95] Hanahan D, Weinberg RA (2000) The hallmarks of cancer. Cell ;100: 57-70.

[96] Hersey P, Zhang XD (2003) Overcoming resistance of cancer cells to apoptosis. J.Cell Physiol ;196: 9-18.

[97] Hockenbery D, Nunez G, Milliman C, Schreiber RD, Korsmeyer SJ (1990) Bcl-2 is an inner mitochondrial membrane protein that blocks programmed cell death. Nature ;348: 334-336.

[98] Tsujimoto Y, Finger LR, Yunis J, Nowell PC, Croce CM (1984) Cloning of the chromosome breakpoint of neoplastic B cells with the $t(14 ; 18)$ chromosome translocation. Science ;226: 1097-1099.

[99] Vaux DL, Cory S, Adams JM (1988) Bcl-2 gene promotes haemopoietic cell survival and cooperates with c-myc to immortalize pre-B cells. Nature ;335: 440-442.

[100] Strasser A, Harris AW, Bath ML, Cory S (1990) Novel primitive lymphoid tumours induced in transgenic mice by cooperation between myc and bcl-2. Nature ;348: 331-333.

[101] Strasser A, Cory S, Adams JM (2011) Deciphering the rules of programmed cell death to improve therapy of cancer and other diseases. EMBO J.30: 3667-3683.

[102] Plati J, Bucur O, Khosravi-Far R (2011) Apoptotic cell signaling in cancer progression and therapy. Integr.Biol.(Camb.) ;3: 279-296.

[103] Rampino N, Yamamoto H, Ionov Y, Li Y, Sawai H, Reed JC, et al. (1997) Somatic frameshift mutations in the BAX gene in colon cancers of the microsatellite mutator phenotype. Science ;275: 967-969.

[104] Tagawa H, Karnan S, Suzuki R, Matsuo K, Zhang X, Ota A, et al. (2005) Genome-wide array-based CGH for mantle cell lymphoma: identification of homozygous deletions of the proapoptotic gene BIM. Oncogene ;24: 1348-1358.

[105] Beroukhim R, Mermel CH, Porter D, Wei G, Raychaudhuri S, Donovan J, et al. (2010) The landscape of somatic copy-number alteration across human cancers. Nature ;463: 899-905. 
[106] Garrison SP, Jeffers JR, Yang C, Nilsson JA, Hall MA, Rehg JE, et al. (2008) Selection against PUMA gene expression in Myc-driven B-cell lymphomagenesis. Mol.Cell Biol.28: 5391-5402.

[107] Richter-Larrea JA, Robles EF, Fresquet V, Beltran E, Rullan AJ, Agirre X, et al. (2010) Reversion of epigenetically mediated BIM silencing overcomes chemoresistance in Burkitt lymphoma. Blood ;116: 2531-2542.

[108] Kashkar H (2010) X-linked inhibitor of apoptosis: a chemoresistance factor or a hollow promise. Clin.Cancer Res.16: 4496-4502.

[109] Kaufmann T, Strasser A, Jost PJ (2012) Fas death receptor signalling: roles of Bid and XIAP. Cell Death.Differ.19: 42-50.

[110] Mita AC, Mita MM, Nawrocki ST, Giles FJ (2008) Survivin: key regulator of mitosis and apoptosis and novel target for cancer therapeutics. Clin.Cancer Res.14: 5000-5005.

[111] Reichert S, Rodel C, Mirsch J, Harter PN, Tomicic MT, Mittelbronn M, et al. (2011) Survivin inhibition and DNA double-strand break repair: a molecular mechanism to overcome radioresistance in glioblastoma. Radiother.Oncol.101: 51-58.

[112] Islam A, Kageyama H, Takada N, Kawamoto T, Takayasu H, Isogai E, et al. (2000) High expression of Survivin, mapped to 17q25, is significantly associated with poor prognostic factors and promotes cell survival in human neuroblastoma. Oncogene ;19: 617-623.

[113] Hattori M, Sakamoto H, Satoh K, Yamamoto T (2001) DNA demethylase is expressed in ovarian cancers and the expression correlates with demethylation of $\mathrm{CpG}$ sites in the promoter region of c-erbB-2 and survivin genes. Cancer Lett.169: 155-164.

[114] Li F, Altieri DC (1999) The cancer antiapoptosis mouse survivin gene: characterization of locus and transcriptional requirements of basal and cell cycle-dependent expression. Cancer Res.59: 3143-3151.

[115] Mesri M, Morales-Ruiz M, Ackermann EJ, Bennett CF, Pober JS, Sessa WC, et al. (2001) Suppression of vascular endothelial growth factor-mediated endothelial cell protection by survivin targeting. Am.J.Pathol.158: 1757-1765.

[116] Zaffaroni N, Daidone MG (2002) Survivin expression and resistance to anticancer treatments: perspectives for new therapeutic interventions. Drug Resist.Updat.5: 65-72.

[117] Rufini A, Melino G (2011) Cell death pathology: the war against cancer. Biochem.Biophys.Res.Commun.414: 445-450.

[118] Li G, Ho VC (1998) p53-dependent DNA repair and apoptosis respond differently to high- and low-dose ultraviolet radiation. Br.J.Dermatol.139: 3-10.

[119] Gabrielli B, Brooks K, Pavey S (2012) Defective cell cycle checkpoints as targets for anti-cancer therapies. Front Pharmacol.3: 9.

[120] Roos WP, Kaina B (2012) DNA damage-induced apoptosis: From specific DNA lesions to the DNA damage response and apoptosis. Cancer Lett.

[121] Hanahan D, Weinberg RA (2011) Hallmarks of cancer: the next generation. Cell ;144: 646-674.

[122] Hers I, Vincent EE, Tavare JM (2011) Akt signalling in health and disease. Cell Signal.23: 1515-1527. 
[123] Sarbassov DD, Guertin DA, Ali SM, Sabatini DM (2005) Phosphorylation and regulation of Akt/PKB by the rictor-mTOR complex. Science ;307: 1098-1101.

[124] Liu P, Cheng H, Roberts TM, Zhao JJ (2009) Targeting the phosphoinositide 3-kinase pathway in cancer. Nat.Rev.Drug Discov.8: 627-644.

[125] Vivanco I, Sawyers CL (2002) The phosphatidylinositol 3-Kinase AKT pathway in human cancer. Nat.Rev.Cancer ;2: 489-501.

[126] Haddad JJ, Abdel-Karim NE (2011) NF-kappaB cellular and molecular regulatory mechanisms and pathways: therapeutic pattern or pseudoregulation? Cell Immunol.271: 5-14.

[127] Hafsi S, Pezzino FM, Candido S, Ligresti G, Spandidos DA, Soua Z, et al. (2012) Gene alterations in the PI3K/PTEN/AKT pathway as a mechanism of drug-resistance (review). Int.J.Oncol.40: 639-644.

[128] Zitvogel L, Apetoh L, Ghiringhelli F, Andre F, Tesniere A, Kroemer G (2008) The anticancer immune response: indispensable for therapeutic success? J.Clin.Invest ;118: 1991-2001.

[129] Garg AD, Krysko DV, Verfaillie T, Kaczmarek A, Ferreira GB, Marysael T, et al. (2012) A novel pathway combining calreticulin exposure and ATP secretion in immunogenic cancer cell death. EMBO J.31: 1062-1079.

[130] Tesniere A, Panaretakis T, Kepp O, Apetoh L, Ghiringhelli F, Zitvogel L, et al. (2008) Molecular characteristics of immunogenic cancer cell death. Cell Death.Differ.15: 3-12.

[131] Chao MP, Jaiswal S, Weissman-Tsukamoto R, Alizadeh AA, Gentles AJ, Volkmer J, et al. (2010) Calreticulin is the dominant pro-phagocytic signal on multiple human cancers and is counterbalanced by CD47. Sci.Transl.Med.2: 63ra94.

[132] Chao MP, Weissman IL, Majeti R (2012) The CD47-SIRPalpha pathway in cancer immune evasion and potential therapeutic implications. Curr.Opin.Immunol.24: 225232.

[133] Leontieva OV, Gudkov AV, Blagosklonny MV (2010) Weak p53 permits senescence during cell cycle arrest. Cell Cycle ;9: 4323-4327.

[134] Rodier F, Campisi J (2011) Four faces of cellular senescence. J.Cell Biol.192: 547-556.

[135] Schmitt CA (2007) Cellular senescence and cancer treatment. Biochim.Biophys.Acta ;1775: 5-20.

[136] Fimia GM, Stoykova A, Romagnoli A, Giunta L, Di BS, Nardacci R, et al. (2007) Ambra1 regulates autophagy and development of the nervous system. Nature ;447: 1121-1125.

[137] Liang C, Feng P, Ku B, Dotan I, Canaani D, Oh BH, et al. (2006) Autophagic and tumour suppressor activity of a novel Beclin1-binding protein UVRAG. Nat.Cell Biol.8: 688-699.

[138] Mehrpour M, Esclatine A, Beau I, Codogno P (2010) Overview of macroautophagy regulation in mammalian cells. Cell Res.20: 748-762.

[139] Ku B, Woo JS, Liang C, Lee KH, Jung JU, Oh BH (2008) An insight into the mechanistic role of Beclin 1 and its inhibition by prosurvival Bcl-2 family proteins. Autophagy.4: 519-520. 
[140] Liang XH, Jackson S, Seaman M, Brown K, Kempkes B, Hibshoosh H, et al. (1999) Induction of autophagy and inhibition of tumorigenesis by beclin 1 . Nature ;402: 672676.

[141] Yue Z, Jin S, Yang C, Levine AJ, Heintz N (2003) Beclin 1, an autophagy gene essential for early embryonic development, is a haploinsufficient tumor suppressor. Proc.Natl.Acad.Sci.U.S.A ;100: 15077-15082.

[142] Qu X, Yu J, Bhagat G, Furuya N, Hibshoosh H, Troxel A, et al. (2003) Promotion of tumorigenesis by heterozygous disruption of the beclin 1 autophagy gene. J.Clin.Invest ;112: 1809-1820.

[143] Matsui Y, Takagi H, Qu X, Abdellatif M, Sakoda H, Asano T, et al. (2007) Distinct roles of autophagy in the heart during ischemia and reperfusion: roles of AMP-activated protein kinase and Beclin 1 in mediating autophagy. Circ.Res.100: 914-922.

[144] Takahashi Y, Coppola D, Matsushita N, Cualing HD, Sun M, Sato Y, et al. (2007) Bif-1 interacts with Beclin 1 through UVRAG and regulates autophagy and tumorigenesis. Nat.Cell Biol.9: 1142-1151.

[145] Ionov Y, Nowak N, Perucho M, Markowitz S, Cowell JK (2004) Manipulation of nonsense mediated decay identifies gene mutations in colon cancer Cells with microsatellite instability. Oncogene ;23: 639-645.

[146] Kim MS, Jeong EG, Ahn CH, Kim SS, Lee SH, Yoo NJ (2008) Frameshift mutation of UVRAG, an autophagy-related gene, in gastric carcinomas with microsatellite instability. Hum.Pathol.39: 1059-1063.

[147] Bekri S, Adelaide J, Merscher S, Grosgeorge J, Caroli-Bosc F, Perucca-Lostanlen D, et al. (1997) Detailed map of a region commonly amplified at 11q13-->q14 in human breast carcinoma. Cytogenet.Cell Genet.79: 125-131.

[148] Lee JW, Jeong EG, Soung YH, Nam SW, Lee JY, Yoo NJ, et al. (2006) Decreased expression of tumour suppressor Bax-interacting factor-1 (Bif-1), a Bax activator, in gastric carcinomas. Pathology ;38: 312-315.

[149] Coppola D, Khalil F, Eschrich SA, Boulware D, Yeatman T, Wang HG (2008) Downregulation of Bax-interacting factor-1 in colorectal adenocarcinoma. Cancer ;113: 26652670.

[150] Cuddeback SM, Yamaguchi H, Komatsu K, Miyashita T, Yamada M, Wu C, et al. (2001) Molecular cloning and characterization of Bif-1. A novel Src homology 3 domaincontaining protein that associates with Bax. J.Biol.Chem.276: 20559-20565.

[151] Yang YP, Liang ZQ, Gu ZL, Qin ZH (2005) Molecular mechanism and regulation of autophagy. Acta Pharmacol.Sin.26: 1421-1434.

[152] Gozuacik D, Kimchi A (2004) Autophagy as a cell death and tumor suppressor mechanism. Oncogene ;23: 2891-2906.

[153] Samuels Y, Velculescu VE (2004) Oncogenic mutations of PIK3CA in human cancers. Cell Cycle ;3: 1221-1224.

[154] Saeki K, Yuo A, Okuma E, Yazaki Y, Susin SA, Kroemer G, et al. (2000) Bcl-2 downregulation causes autophagy in a caspase-independent manner in human leukemic HL60 cells. Cell Death.Differ.7: 1263-1269. 
[155] Pattingre S, Tassa A, Qu X, Garuti R, Liang XH, Mizushima N, et al. (2005) Bcl-2 antiapoptotic proteins inhibit Beclin 1-dependent autophagy. Cell ;122: 927-939.

[156] Maiuri MC, Le TG, Criollo A, Rain JC, Gautier F, Juin P, et al. (2007) Functional and physical interaction between Bcl-X(L) and a BH3-like domain in Beclin-1. EMBO J.26: 2527-2539.

[157] Mathew R, Kongara S, Beaudoin B, Karp CM, Bray K, Degenhardt K, et al. (2007) Autophagy suppresses tumor progression by limiting chromosomal instability. Genes Dev.21: 1367-1381.

[158] Karantza-Wadsworth V, Patel S, Kravchuk O, Chen G, Mathew R, Jin S, et al. (2007) Autophagy mitigates metabolic stress and genome damage in mammary tumorigenesis. Genes Dev.21: 1621-1635.

[159] Tasdemir E, Maiuri MC, Galluzzi L, Vitale I, Djavaheri-Mergny M, D'Amelio M, et al. (2008) Regulation of autophagy by cytoplasmic p53. Nat.Cell Biol.10: 676-687.

[160] Zong WX, Thompson CB (2006) Necrotic death as a cell fate. Genes Dev.20: 1-15.

[161] Balkwill F, Charles KA, Mantovani A (2005) Smoldering and polarized inflammation in the initiation and promotion of malignant disease. Cancer Cell ;7: 211-217.

[162] Vakkila J, Lotze MT (2004) Inflammation and necrosis promote tumour growth. Nat.Rev.Immunol.4: 641-648.

[163] Degenhardt K, Mathew R, Beaudoin B, Bray K, Anderson D, Chen G, et al. (2006) Autophagy promotes tumor cell survival and restricts necrosis, inflammation, and tumorigenesis. Cancer Cell ;10: 51-64.

[164] Boya P, Gonzalez-Polo RA, Casares N, Perfettini JL, Dessen P, Larochette N, et al. (2005) Inhibition of macroautophagy triggers apoptosis. Mol.Cell Biol.25: 1025-1040.

[165] Majmundar AJ, Wong WJ, Simon MC (2010) Hypoxia-inducible factors and the response to hypoxic stress. Mol.Cell ;40: 294-309.

[166] Mazure NM, Pouyssegur J (2010) Hypoxia-induced autophagy: cell death or cell survival? Curr.Opin.Cell Biol.22: 177-180.

[167] Bellot G, Garcia-Medina R, Gounon P, Chiche J, Roux D, Pouyssegur J, et al. (2009) Hypoxia-induced autophagy is mediated through hypoxia-inducible factor induction of BNIP3 and BNIP3L via their BH3 domains. Mol.Cell Biol.29: 2570-2581.

[168] Rabinowitz JD, White E (2010) Autophagy and metabolism. Science ;330: 1344-1348.

[169] Fung C, Lock R, Gao S, Salas E, Debnath J (2008) Induction of autophagy during extracellular matrix detachment promotes cell survival. Mol.Biol.Cell ;19: 797-806.

[170] Kenific CM, Thorburn A, Debnath J (2010) Autophagy and metastasis: another doubleedged sword. Curr.Opin.Cell Biol.22: 241-245.

[171] Debnath J (2008) Detachment-induced autophagy during anoikis and lumen formation in epithelial acini. Autophagy.4: 351-353.

[172] Yerbes R, Palacios C, Lopez-Rivas A (2011) The therapeutic potential of TRAIL receptor signalling in cancer cells. Clin.Transl.Oncol.13: 839-847.

[173] Ashkenazi A, Dixit VM (1998) Death receptors: signaling and modulation. Science ;281: 1305-1308. 
[174] Nguyen T, Zhang XD, Hersey P (2001) Relative resistance of fresh isolates of melanoma to tumor necrosis factor-related apoptosis-inducing ligand (TRAIL)-induced apoptosis. Clin.Cancer Res.7: 966s-973s.

[175] Pavet V, Portal MM, Moulin JC, Herbrecht R, Gronemeyer H (2011) Towards novel paradigms for cancer therapy. Oncogene ;30: 1-20.

[176] Hetschko H, Voss V, Seifert V, Prehn JH, Kogel D (2008) Upregulation of DR5 by proteasome inhibitors potently sensitizes glioma cells to TRAIL-induced apoptosis. FEBS J.275: 1925-1936.

[177] Johnstone RW, Frew AJ, Smyth MJ (2008) The TRAIL apoptotic pathway in cancer onset, progression and therapy. Nat.Rev.Cancer ;8: 782-798.

[178] Speirs CK, Hwang M, Kim S, Li W, Chang S, Varki V, et al. (2011) Harnessing the cell death pathway for targeted cancer treatment. Am.J.Cancer Res.1: 43-61.

[179] Martinez-Lostao L, Marzo I, Anel A, Naval J (2012) Targeting the Apo2L/TRAIL system for the therapy of autoimmune diseases and cancer. Biochem.Pharmacol.83: 1475-1483.

[180] Aggarwal BB (2003) Signalling pathways of the TNF superfamily: a double-edged sword. Nat.Rev.Immunol.3: 745-756.

[181] Holler N, Zaru R, Micheau O, Thome M, Attinger A, Valitutti S, et al. (2000) Fas triggers an alternative, caspase-8-independent cell death pathway using the kinase RIP as effector molecule. Nat.Immunol.1: 489-495.

[182] Vanden Berghe T, van LG, Saelens X, Van GM, Brouckaert G, Kalai M, et al. (2004) Differential signaling to apoptotic and necrotic cell death by Fas-associated death domain protein FADD. J.Biol.Chem.279: 7925-7933.

[183] Tarhini AA, Kirkwood JM (2007) Oblimersen in the treatment of metastatic melanoma. Future.Oncol.3: 263-271.

[184] Heidari N, Hicks MA, Harada H (2010) GX15-070 (obatoclax) overcomes glucocorticoid resistance in acute lymphoblastic leukemia through induction of apoptosis and autophagy. Cell Death.Dis.1: e76.

[185] McCoy F, Hurwitz J, McTavish N, Paul I, Barnes C, O'Hagan B, et al. (2010) Obatoclax induces Atg7-dependent autophagy independent of beclin-1 and BAX/BAK. Cell Death.Dis.1: e108.

[186] Oltersdorf T, Elmore SW, Shoemaker AR, Armstrong RC, Augeri DJ, Belli BA, et al. (2005) An inhibitor of Bcl-2 family proteins induces regression of solid tumours. Nature ;435: 677-681.

[187] van Delft MF, Wei AH, Mason KD, Vandenberg CJ, Chen L, Czabotar PE, et al. (2006) The BH3 mimetic ABT-737 targets selective Bcl-2 proteins and efficiently induces apoptosis via Bak/Bax if Mcl-1 is neutralized. Cancer Cell ;10: 389-399.

[188] Cragg MS, Harris C, Strasser A, Scott CL (2009) Unleashing the power of inhibitors of oncogenic kinases through BH3 mimetics. Nat.Rev.Cancer ;9: 321-326.

[189] Carrington EM, Vikstrom IB, Light A, Sutherland RM, Londrigan SL, Mason KD, et al. (2010) BH3 mimetics antagonizing restricted prosurvival Bcl-2 proteins represent another class of selective immune modulatory drugs. Proc.Natl.Acad.Sci.U.S.A ;107: 10967-10971. 
[190] Chen DJ, Huerta S (2009) Smac mimetics as new cancer therapeutics. Anticancer Drugs ;20: 646-658.

[191] Straub CS (2011) Targeting IAPs as an approach to anti-cancer therapy. Curr.Top.Med.Chem.11: 291-316.

[192] Gyrd-Hansen M, Meier P (2010) IAPs: from caspase inhibitors to modulators of NFkappaB, inflammation and cancer. Nat.Rev.Cancer ;10: 561-574.

[193] Kaelin WG, Jr. (2009) Synthetic lethality: a framework for the development of wiser cancer therapeutics. Genome Med.1: 99.

[194] Chan DA, Giaccia AJ (2011) Harnessing synthetic lethal interactions in anticancer drug discovery. Nat.Rev.Drug Discov.10: 351-364.

[195] Bolderson E, Richard DJ, Zhou BB, Khanna KK (2009) Recent advances in cancer therapy targeting proteins involved in DNA double-strand break repair. Clin.Cancer Res.15: 6314-6320.

[196] Dai Y, Grant S (2010) New insights into checkpoint kinase 1 in the DNA damage response signaling network. Clin.Cancer Res.16: 376-383.

[197] Calvert H, Azzariti A (2011) The clinical development of inhibitors of poly(ADPribose) polymerase. Ann.Oncol.22 Suppl 1: i53-i59.

[198] Javle M, Curtin NJ (2011) The potential for poly (ADP-ribose) polymerase inhibitors in cancer therapy. Ther.Adv.Med.Oncol.3: 257-267.

[199] Imre G, Larisch S, Rajalingam K (2011) Ripoptosome: a novel IAP-regulated cell deathsignalling platform. J.Mol.Cell Biol.3: 324-326.

[200] Safa AR, Pollok KE (2011) Targeting the Anti-Apoptotic Protein c-FLIP for Cancer Therapy. Cancers.(Basel) ;3: 1639-1671.

[201] Maiuri MC, Zalckvar E, Kimchi A, Kroemer G (2007) Self-eating and self-killing: crosstalk between autophagy and apoptosis. Nat.Rev.Mol.Cell Biol.8: 741-752.

[202] Chen N, Karantza-Wadsworth V (2009) Role and regulation of autophagy in cancer. Biochim.Biophys.Acta ;1793: 1516-1523.

[203] Carew JS, Nawrocki ST, Kahue CN, Zhang H, Yang C, Chung L, et al. (2007) Targeting autophagy augments the anticancer activity of the histone deacetylase inhibitor SAHA to overcome Bcr-Abl-mediated drug resistance. Blood ;110: 313-322.

[204] Apel A, Herr I, Schwarz H, Rodemann HP, Mayer A (2008) Blocked autophagy sensitizes resistant carcinoma cells to radiation therapy. Cancer Res.68: 1485-1494.

[205] Nahta R, Yuan LX, Zhang B, Kobayashi R, Esteva FJ (2005) Insulin-like growth factor-I receptor/human epidermal growth factor receptor 2 heterodimerization contributes to trastuzumab resistance of breast cancer cells. Cancer Res.65: 11118-11128.

[206] Esparis-Ogando A, Ocana A, Rodriguez-Barrueco R, Ferreira L, Borges J, Pandiella A (2008) Synergic antitumoral effect of an IGF-IR inhibitor and trastuzumab on HER2overexpressing breast cancer cells. Ann.Oncol.19: 1860-1869.

[207] Ropero S, Menendez JA, Vazquez-Martin A, Montero S, Cortes-Funes H, Colomer R (2004) Trastuzumab plus tamoxifen: anti-proliferative and molecular interactions in breast carcinoma. Breast Cancer Res.Treat.86: 125-137.

[208] Yang S, Wang X, Contino G, Liesa M, Sahin E, Ying H, et al. (2011) Pancreatic cancers require autophagy for tumor growth. Genes Dev.25: 717-729. 
[209] Guo JY, Chen HY, Mathew R, Fan J, Strohecker AM, Karsli-Uzunbas G, et al. (2011) Activated Ras requires autophagy to maintain oxidative metabolism and tumorigenesis. Genes Dev.25: 460-470.

[210] Abe A, Yamada H, Moriya S, Miyazawa K (2011) The beta-carboline alkaloid harmol induces cell death via autophagy but not apoptosis in human non-small cell lung cancer A549 cells. Biol.Pharm.Bull.34: 1264-1272.

[211] Yu L, Alva A, Su H, Dutt P, Freundt E, Welsh S, et al. (2004) Regulation of an ATG7beclin 1 program of autophagic cell death by caspase-8. Science ;304: 1500-1502.

[212] Yu L, Wan F, Dutta S, Welsh S, Liu Z, Freundt E, et al. (2006) Autophagic programmed cell death by selective catalase degradation. Proc.Natl.Acad.Sci.U.S.A ;103: 4952-4957.

[213] Lum JJ, DeBerardinis RJ, Thompson CB (2005) Autophagy in metazoans: cell survival in the land of plenty. Nat.Rev.Mol.Cell Biol.6: 439-448.

[214] Wu YT, Tan HL, Huang Q, Kim YS, Pan N, Ong WY, et al. (2008) Autophagy plays a protective role during zVAD-induced necrotic cell death. Autophagy.4: 457-466.

[215] Amaravadi RK, Thompson CB (2007) The roles of therapy-induced autophagy and necrosis in cancer treatment. Clin.Cancer Res.13: 7271-7279.

[216] Lieberthal W, Triaca V, Levine J (1996) Mechanisms of death induced by cisplatin in proximal tubular epithelial cells: apoptosis vs. necrosis. Am.J.Physiol ;270: F700-F708.

[217] Healy E, Dempsey M, Lally C, Ryan MP (1998) Apoptosis and necrosis: mechanisms of cell death induced by cyclosporine A in a renal proximal tubular cell line. Kidney Int.54: 1955-1966.

[218] Chan FK, Shisler J, Bixby JG, Felices M, Zheng L, Appel M, et al. (2003) A role for tumor necrosis factor receptor-2 and receptor-interacting protein in programmed necrosis and antiviral responses. J.Biol.Chem.278: 51613-51621.

[219] Cho DH, Jo YK, Hwang JJ, Lee YM, Roh SA, Kim JC (2009) Caspase-mediated cleavage of ATG6/Beclin-1 links apoptosis to autophagy in HeLa cells. Cancer Lett.274: 95-100.

[220] Djavaheri-Mergny M, Maiuri MC, Kroemer G (2010) Cross talk between apoptosis and autophagy by caspase-mediated cleavage of Beclin 1. Oncogene ;29: 1717-1719.

[221] Hou W, Han J, Lu C, Goldstein LA, Rabinowich H (2010) Autophagic degradation of active caspase-8: a crosstalk mechanism between autophagy and apoptosis. Autophagy.6: 891-900. 